\title{
Information Flow from COVID-19 Pandemic to Islamic and Conventional Equities: An ICEEMDAN-Induced Transfer Entropy Analysis
}

\author{
Ahmed Bossman \\ Department of Finance, School of Business, University of Cape Coast, Cape Coast, Ghana \\ Correspondence should be addressed to Ahmed Bossman; ahmed.bossman@outlook.com
}

Received 1 November 2021; Accepted 15 December 2021; Published 31 December 2021

Academic Editor: Paulo Jorge Silveira Ferreira

Copyright (c) 2021 Ahmed Bossman. This is an open access article distributed under the Creative Commons Attribution License, which permits unrestricted use, distribution, and reproduction in any medium, provided the original work is properly cited.

\begin{abstract}
With the steady growth in the data set on the COVID-19 pandemic, empirical works that employ novel and yet appropriate statistical techniques to corroborate previous findings of the pandemic and its consequences on financial markets are necessary. This paper examined the impact of COVID-19 information flow on the Islamic and conventional equities within the short-, mid-, and long-term horizons to assess possible diversification prospects in the era of the pandemic. To the studied equities markets, a novel technique based on a denoised frequency-domain entropy paradigm was applied. The operability of entrenched market dynamics in the long-term horizon of the COVID-19 pandemic period is reinforced by the results. The findings divulge diversification opportunities between Islamic and conventional equities in the short- and mid-term periods of the COVID-19 pandemic. The risks on equities from Japan or Bahrain could be diversified by equities from Jordan in the short-term, while in the intermediate-term stocks from Japan could diversify with the UAE and USA equities. The results imply that it is imperative for investors and fund managers to employ portfolio management techniques that show how to use benefits together with risk prevention and management across distinct time scales.
\end{abstract}

\section{Introduction}

The global financial crisis (GFC) of 2008-09 and the European sovereign debt crises (ESDC) of 2010-12 highlighted the last decade. These chaotic times raised financial market comovements, resulting in financial contagion and elevated portfolio risk [1-3]. Islamic stock markets grew at a phenomenal rate during both times. The recent COVID-19 pandemic cannot be sidelined when the discourse about financial market turmoil is at play. The pandemic, which has led financial markets to record-breaking losses [4], has driven several studies in the area of cryptocurrencies $[5,6]$, prices of staple foods [7], global equities [8], among others. Arguably, the motivation(s) for these studies has (have) been partly driven by the opportunities for safe haven, diversifier, or hedge assets during the turbulent market period aroused by the pandemic.
During times of financial and economic turmoil, portfolio diversification becomes even more important for investors. However, achieving optimal returns through adequate diversification necessitates a thorough understanding of the risk and return characteristics of various assets in a portfolio, as well as their connectedness and response to market information. The search for reliable assets that may shield investors in these unstable market periods is increased due to the increased information flow to financial markets in crises periods. This is what Owusu Junior et al. [8] terms as the competitive market hypothesis (CMH). The search for safety nets during these times is what triggers financialisation [9], which results in the introduction of new assets and/or asset classes like cryptocurrencies, faith-based financial instruments, Islamic assets, and so forth.

When it comes to alternative financial techniques, Islamic finance is becoming a hot topic, with scholars debating 
it and investors putting it into practice all over the world [10]. Islamic finance is defined by financial activities which are based on Islamic norms and regulations (i.e., the Shariah). It is likewise based on Islamic law-compliant assetbased investments, which are low-risk investments with moderate returns. Aside from its relative resilience in previous crisis periods [10-12], Islamic equities have become more popular as a way for investors to incorporate their religious beliefs into their portfolios.

According to $\mathrm{Ng}$, Chin, and Chong [13], the Islamic Finance Development Indicator (IFDI) in 2018 confirmed the Islamic financial markets' (IFMs) long-term viability by demonstrating the outstanding growth, as seen by an annual growth rate of roughly $11 \%$, making it enticing to investors. Notwithstanding, the prevailing crisis in global financial markets, which is championed by the COVID-19 pandemic, has not only impacted conventional markets; IFMs have had their "fair" share [14] to the extent that recognised rating agencies like S\&P projected that the IFM would decline in growth in 2020, followed by a slight rebound in 2021 [15].

Although both conventional markets and IFMs have witnessed the effect of the COVID-19 pandemic, the magnitude is not the same across these broad markets. The stock market in Pakistan, which is classified as an emerging stock market, was impacted by COVID-19 in a minor way [14] and has been linked to national restrictions imposed during the early days of the pandemic [16]. However, this occurrence contrasted with the conditions of advanced stock markets, like in the United States, where the COVID-19 pandemic had a substantial impact on the markets [17]. These pieces of data provide some preliminary insight into the nature of international equities markets' responses to the COVID-19 pandemic. The differences in the observed impact on equities markets, in line with Ahmed [16], could be ascribed to the disparities in policy responses towards fighting the pandemic. These policy responses are expected to transmit different information across equities markets.

To combat the virus's spread, several governments across the globe imposed a variety of restrictions on people's movements, including inter- and intraborder travel bans, lockdowns or stay-at-home restrictions, closures of places of worship and educational institutions, and social distancing $[7,8]$. These policy measures on fighting the pandemic could heighten or lessen unemployment, which also impacts business and economic activities. Consequently, business earnings are also affected, resulting in plummeting share values. Thus, COVID-19 information flows could impact stock performance through the slowdown in macroeconomic performance. Impliedly, these initial responses may take time to reflect in the real economy and, hence, with sufficient data and for over a year into the pandemic, the effect of the information flow from the pandemic towards equities could be examined using the appropriate technique.

The Islamic and conventional markets, given the disparities in their operational principles, serve as separate asset classes to investors. Given the relative "sufficiency" of existing data on the pandemic and the fact that the pandemic has stayed with investors for at least a year, this study proposes that investors have been presented with sufficient information over a longer period to rebalance or readjust their portfolio holdings in search for optimal portfolios. Furthermore, much of the existing literature [18-24] have focused on spillovers across markets in the era of the COVID-19 pandemic with little attention on the transmission mechanism of the pandemic. This impacted research like Asafo-Adjei et al. [5] and Owusu Junior et al. [8], contributing to closing the gap by employing transfer entropy to assess information flow between financial markets.

These works, on the other hand, are focused on cryptocurrencies and stock markets, as well as worldwide equity markets. To the best of knowledge that rests with the extant literature, a comparative study of the information flows to Islamic and conventional markets is nonexistent. This informs and contextualises this study as it focuses on the G7 and Islamic equities markets alongside some selected market indices to assess whether information flow from the COVID-19 pandemic leaves behind diversification prospects for global equities investors.

As indicated by Al-Yahyaee et al. [9], sector comovements fluctuate with time and frequency and are influenced by significant events. This warrants that where data is available to a usable extent, studies that investigate the index-specific response to a significant event like the COVID-19 pandemic are not out of play. From this backcloth, this study addresses three questions: (i) Are there differences in the way Islamic and conventional equities respond to information flow from COVID-19? (ii) Are there diversification prospects for Islamic and conventional equities in the post-COVID-19 era? (iii) At what time scale(s) could diversification be achieved?

Empirical responses to these research questions need to be tackled from a comprehensive approach that incorporates investor complexities $[8,25,26]$. Huynh et al. [27] reveal that, in the tumult trading phase of the COVID-19 pandemic era, stock markets are characterised by huge information structures, which are likely to result in negative bubbles. Corollary to investor complexities and negative bubbles, this study employs a data-intensive approach to delineate composite data into various time scales after comprehensively dealing with noisy observations. This would enable a relative effective assessment by quantifying the information flow from COVID-19 to equities markets. The transfer entropy hinged on the improved ensemble empirical mode decomposition with adaptive noise (ICEEMDAN) approach to decomposition, which is novel to the extant literature, is employed.

The ICEEMDAN-based entropy facilitates the assessment of the amount of information flow to account for huge tails in the studied markets' equities returns across distinct time horizons. According to Wu et al. [28], the ICEEMDAN decomposes time series into inherent mode functions (IMFs) at multiple time scales due to its data-intensive nature. The decomposition methods are empirical and adaptive, and they are designed to account for nonstationary, nonlinear, and complex data while making no assumptions about their characteristics [28-30]. The ICEEMDAN outperforms the variational mode decomposition (VMD) [28] and wavelet-based decompositions [30]. Several scholars $[28,31,32]$ have resorted to the ICEEMDAN technique to investigate the dynamics of economic 
markets due to the relative advantages it possesses over other decomposition techniques from the family of the empirical mode decompositions (EMDs) of Huang [33], which are considered superior on their own notwithstanding their limitations [30].

The EMD, for instance, has been critiqued for a "mode mixing" issue. The ensemble EMD (EEMD) designed to counteract the limitations of the EMD through the introduction of the white Gaussian noise also comes with its limitation such that the aggregate of the modes, the reconstructed signal, and the final trend produced from the algorithm are rooted with residual noise; also, a varied number of modes are likely to be generated, which makes the final averaging difficult [34]. The complementary ensemble EMD was further designed to overcome the reconstruction limitation of the EEMD through the use of paired complementary noise, but the completeness property is not yet proven; also, the final averaging limitation remains unresolved, since a variable number of modes could be generated by different copies of the signal [34].

Lastly, on the family of EMDs, the complete EEMD with adaptive noise (CEEMDAN) technique was developed to offer an essential advancement over the EEMD by reaching a minimal reconstruction error and dealing with the limitation of a varying number of modes for different signal plus noise realisations and has been satisfactorily employed in areas like biomedical engineering [35], building energy consumption [36], seismology [37, 38], and financial markets $[8,30]$.

Despite the satisfactory attention received in diverse fields, CEEMDAN still has certain drawbacks. The modes produced by CEEMDAN come with residual noise, and the signal information appears "later" in CEEMDAN than in EEMD, with some "spurious" modes in the early phases of the decomposition [34]. An observation of the signals studied in the works of Colominas, Schlotthauer, Flandrin, and Torres [39] and Torres, Colominas, Schlotthauer, and Flandrin [40] reveals that the first two or three modes yield a significant amount of noise and comparable signal scales. In this study, these two drawbacks are addressed by employing the improved form of the complete ensemble empirical mode decomposition with adaptive noise, the ICEEMDAN technique.

In addition to the novel decomposition approach, the ICEEMDAN, the Rényi entropy, a unique form of entropy that applies appropriate weights to distinguish tailed distributions, is employed in this study. Financial assets contain wide tails, which the Shannon entropy cannot account for. These fat tails, which must be accounted for, are especially powerful in turbulent trading periods such as the one introduced by the COVID-19. Transfer entropy (TE) is a new technique for measuring causal influences which captures model-free information flow measurement, does not rely on data structure or linearity, and is resistant to spurious associations, making it a novel technique for traditional causality frameworks such as the Granger causality test [27]. This method is also noted for estimating the flow of information between "two" return series, and it is widely used in a variety of scientific fields.
Given the relevancy of TEs in examining information flow between dual time series, it is necessary to employ the appropriate form of transfer entropy. Shannon entropy (SE) is one form of entropy that has been prevalently employed in studying financial data series. Nonetheless, it has substantial drawbacks that need to be dealt with [41]. In the course of data distribution, $\mathrm{SE}$ is ineffective in attributing equal weights to distinct sections $[42,8]$. The SE form of entropy does not account for fat tails, which are common to financial time series [8]. These fat tails seem stronger in pandemics like the COVID-19 [8] and need to be dealt with accordingly [43]. By introducing a weighting parameter (as the methodology details), the Rényian entropy overcomes this drawback of SE. This renders the Rényi entropy a suitable form of transfer entropy to be used in this study.

This study's major contributions are summarised as follows. First, the study employs the ICEEMDAN, which corrects the flaws of subjective wavelet decomposition, which is rarely employed to investigate correlations across time scales [28-30]. It also overcomes the shortfalls of the CEEMDAN and other decomposition techniques, which may leave behind residual noise in the model and may also be associated with spurious mode problems. Second, no previous research has used transfer entropy analysis to analyse the association between COVID-19 and equities markets based on ICEEMDAN, per the existing literature. This paper examines dynamic correlation over the short-, mid-, and long-term horizons using the Rényi transfer entropy (RTE) approach. Third, frequency decompositions themselves provide a method for assessing the pandemic's ostensibly negative impact on various time scales. This allows economic actors and governments to change their judgments (policy actions) vis-à-vis the going concern based on the flexibility and variety of market players. Lastly, the study is centred on Islamic and conventional equities, which serve as major asset classes on their own. The study helps to reveal diversification, safe haven, and hedging prospects among these asset classes over diverging time scales.

From the findings, the ETEs at the composite level suggest no diversification prospect between Islamic and conventional equities. At the frequency-domain level, the findings divulge some portfolio diversification potentials in the short- and intermediate-terms only. The study finds that the long term presents different dynamics where the majority of the ETEs are insignificantly positive, suggesting that Islamic and conventional markets are almost saturated with COVID-19 information flow.

In addition to Section 1 are Sections 2-6, which, respectively, address a review of the literature, the methods used, data and preliminary analysis, empirical results and discussion, and conclusions.

\section{Literature Review}

Fama et al. [44] establish theoretically that financial markets respond to information, which is expected to render them efficient [45, 46]. In the spirit of Benthall's [47] situated information flow theory (SIFT), causal relations are retrievable amid financial markets (assets) due to mutual 
information sharing. The SIFT uses the philosophy of Odegard [48] and the statistics of Pearl [49] to generate quantified intrinsic information common to two random variables. If the relationship between two random variables could be inferred by way of analysing the extent to which one of the variables could learn the state of the other through observation, then there is mutual information shared by the variables [47]. In the context of this study, stock markets cannot affect COVID-19 case counts and, hence, a one-way flow where stocks are likely to observe the behaviour of COVID-19 related information flow through the mutual and intrinsic information they share in the COVID-19 pandemic era is considered. The study proposes that the responses offered by Islamic and conventional stock markets to information flow from COVID-19 would most likely differ across investment horizons owing to investor complexities and this could result in diversification prospects between Islamic and conventional stock markets.

The complexity of investor demands rekindles the fundamental notion of portfolio diversification. Based on Markowitz's [50] modern portfolio theory, it could be recognised that there are alternative markets (assets and/or asset classes) in which investors deliberately devote a portion, or all, of their investment to one of two overriding goals: portfolio return (risk) maximisation (minimisation). As a result, investors adopt an acceptable portfolio objective based on the time horizon and market conditions, ensuring that the marginal returns produced by the additional assets they include in their portfolios outweigh the marginal risks associated with their inclusion. The fulfilment of any of these competing goals prompts investors to look for assets that may provide safety nets throughout a wide range of time frames, especially in stressful trading periods.

During market crises, the heterogeneity of financial markets across jurisdictions increases, causing investors to respond to information flows in the market in a variety of ways. This indicates that investor behaviour, particularly in the face of crises, will vary over time. Besides, the peculiar differences in IFMs and conventional markets are likely to trigger unique investment responses in turbulent trading periods. The above reasons show that investors' behaviour during volatile market times is asymmetric and time-based, which is reflected in assets' market prices. These circumstances, although oppose the efficient market hypothesis (EMH) [45, 46], support the adaptive and heterogeneous markets hypotheses, AMH [51] and $\mathrm{HMH}$ [52], respectively. The adaptability and heterogeneity of markets have been shown in recent literature [53-55].

The AMH proposes that structural changes drive the establishment of markets, resulting in time-varying market efficiencies. Investors analyse their risk and return preferences in making investment decisions over various time scales, according to the $\mathrm{HMH}$, after taking into account historical and present news items. These theories or market hypotheses imply that empirical research should take into consideration temporal scales that represent the time dynamics of investor behaviour. Corollary to the heterogeneity and adaptability of investors, time could be redefined as the inherent time that runs parallel to short-, intermediate-, and long-term perspectives. In the context of asset pricing and returns, the time-dependent dynamism of investor behaviour causes noise, nonstationarity, nonlinearity, and asymmetry. As a result, empirical studies involving financial assets must apply approaches that account for all of these complications.

The Islamic and conventional equities markets have received satisfactory attention [56-58]; yet they do not capture the prevailing recent episodes of financial crises like the COVID-19 pandemic era. A similar observation is made with Umar et al.'s [59] study, which focused on Shariahcompliant equities only. The body of knowledge holds records for some empirical works covering the impact of COVID-19 on financial markets. Spillover and asset allocation [60-62], commodities markets [63-65], environmental, social, and governance (ESG) indices $[60,66]$, currencies, cryptocurrencies, and fiat currencies $[60,67,68]$, bond markets [69], and so forth have been the focus of the initial strand of literature spanning over the era of the COVID-19 pandemic.

A distinct strand of literature $[60,66,68,70,71]$ has examined the impact of media coverage index (MCI) on financial markets with a few on cryptocurrencies $[5,60,67,68]$. A predominant approach employed by the studies belonging to this stand of literature is the wavelet analysis [60, 66-68].

These studies largely reveal time- and frequency-dependent diversification opportunities between the studied financial markets. Notwithstanding, these works are limited by the decomposition approach, the wavelet technique. While recent techniques such as the Fourier transform [72], wavelets transform [73], and adaptive optimal-kernel timefrequency representation $[74,75]$ have been employed in capturing frequency patterns in financial time series, they either insufficiently detect and reduce noise or fail to account for it $[76,77]$. As an additional drawback of the wavelets approach, the number of IMFs is exogenously determined, allowing the researcher to impose an arbitrary scale that may contradict theory [76], which may bias the results and conclusions generated. Besides, the existing studies, per their methods, fail to quantify the flow of information from the COVID-19 pandemic to Islamic and conventional equities markets.

Owing to the exuberant market dynamics during the COVID-19's tumultuous trading phase, stock markets will have huge information structures, which, according to Huynh et al. [27] may result in negative bubbles. Corollary to these negative bubbles, the right approach must be used to quantify information flow within financial markets. In terms of the driving and responding transfer for two or more variables changing in time, a theoretic measure of information may be determined. This is what Schreiber [78] defines as the transfer entropy (TE).

Several empirical researches have employed the TE to investigate the impact of COVID-19 on the global economy. In their study, Lahmiri and Bekiros [79] used the "Largest Lyapunov Exponent" (LLE), which is based on the Rosenstein approach and approximation entropy. One of the main reasons for their study is the method's ability to 
accommodate small samples. At this stage of the pandemic, the sample has increased considerably. The body of knowledge on the frequency-domain connectivity of COVID-19 and stocks markets within the context of information transmission is expanding. Lahmiri and Bekiros [42] studied the impact of COVID-19 on the unpredictability of international stock volatilities using the Shannon entropy wavelet transform domain. Using multiscale transfer entropy, Wang J. and Wang X. [80] investigated the impact of COVID-19 on important global stocks, currencies, and Bitcoin. On the one hand, these studies are hampered by small sample bias, and, on the other hand, they used Shannon entropy, which is prone to assigning different regions of the data distribution similar weights (see [8]).

More recently, Ferreira et al. [81] employed the transfer entropy approach to examine the bidirectional connectedness between leading Central Eastern European Countries (CEEC) stock markets. The authors found significant comovements between CEEC equities. By employing static and dynamic methods, Ferreira et al. [82] examined the connectedness between energy commodities and energy equities. The transfer entropy analysis revealed that clean energy equities respond to WTI oil price movements. As a drawback to these studies, they do not delineate signals into multiple scales to represent investment horizon and thus investor complexities, adaptability, and heterogeneity of financial markets [53-55] are not catered for.

Corollary to the limitations in the extant literature, this work is one of the few in the literature that uniquely tackles these gaps. The entropy methodology grounded on the Improved Complete Ensemble Empirical Mode Decomposition with Adaptive Noise (ICEEMDAN), a data-driven methodology, is employed to assess the flow of information from COVID-19 to Islamic and conventional equities. As a result, the study covers a longer sample period, which is necessary to better understand the intricacies of investor behaviour within and across IFMs and conventional markets in the era of the COVID-19 pandemic.

\section{Methods}

The methodological approach consists of two phases. First, the ICEEMDAN approach is used to decompose the return series into IMFs, which represent intrinsic time, and is divided into short-, intermediate-, and long-term horizons. This decomposition facilitates the examination of COVID19's impact throughout a range of decision-making time horizons. Second, the Rényi transfer entropy (RTE) specification is employed to calculate effective transfer entropy (ETE). Quantification of the flow of information from COVID-19 to equities markets is done by the RTE by giving more weight to the "ends" of distributions, which corresponds to the stylised realities of financial assets.

In a nonparametric fashion, nonstationarity, nonlinearity, and asymmetry in the series are handled by these techniques [83]. The one-sided information flow from the COVID-19 pandemic to the Islamic and conventional equities is the focus of this study. It is only natural that no information is sent from the equities to COVID-19.
Corollary to this, no decomposition is made of the COVID19 series since, unlike an investor who adjusts his decisions over time, COVID-19 is not an economic agent to make judgments.

3.1. ICEEMDAN. It has been long understood by economists that the connectedness of variables in terms of direction, degree, and shape is distinct across time scales [84]. Nonetheless, until recently, there were no methods available to delineate economic data series into all orthogonal timescale components. Additionally, the instruments to cope with noise, which often dominates short-term financial asset series $[84,85]$, are now accessible. The latest constituent of the empirical mode decomposition (EMD) family, the ICEEMDAN, from Huang [33], is a good example. The signal-to-noise ratio (SNR) minimisation of mode decompositions in unsteady-state signals, efficiency, and reconstruction accuracy are the ICEEMDAN's strengths [86]. In comparison to other versions, Colominas et al.'s [34] ICEEMDAN has the best of these properties. In addition to handling spurious modes and the presence of residual noise in the modes, the persistence of a significant amount of noise and comparable signal scales, which are a limitation of the CEEMDAN, are handled by the ICEEMDAN [34]. While the CEEMDAN performs a better job of eliminating noise, reconstructing the signal, and finding SNR [30], it falls short on two fronts: (i) residual noise is included in the model, as well as (ii) spurious mode problem, as Li et al. [29] identify.

Adapted from Li et al. [29] and in line with Colominas et al.'s (2014) specifications, the ICEEMDAN algorithm is summarised as follows:

Step I: a white noise $\tau_{1}\left[\omega^{(i)}\right]$ is appended to a signal $x$, to yield a new series

$$
x^{(i)}=x+\rho_{0}\left(\omega^{(i)}\right), \quad i=1,2, \ldots, N,
$$

where $\omega^{(i)}, \rho_{0}$, and $N$ are, respectively, the $i$-th white noise added, SNR, and the amount of white noise appended.

Step II: estimation of the local mean of $x^{(i)}$ is made using EMD to retrieve the first residual

$$
r_{1}=\left(\frac{1}{N}\right) \sum_{i=1}^{N} M\left(x^{(i)}\right),
$$

from which first IMF $c_{1}=x-r_{1}$ can be obtained.

Step III: recursively obtain the $k$-th IMF $c_{k}=r_{k-1}-r_{k}$, for $k \geq 2$, where

$$
r_{k}=\left(\frac{1}{N}\right) \sum_{i=1}^{N} M\left(r_{k-1}+\rho_{k-1} \tau_{k}\left(\omega^{(i)}\right)\right) .
$$

Flandrin et al. [87]; Gledhill [88]; Wu and Huang [89]; Torres, Colominas, Schlotthauer, and Flandrin [40]; and Li et al. [29] could be referred to for additional notes on the EMD family. 
The ICEEMDAN approach results in decompositions ensuring that the residual noise and the mean value problems caused by the varied numbers of IMFs created by EEMD are substantially reduced $[29,34]$. In line with Colominas et al. [34], throughout the decompositions, default experimental parameters (e.g., for maximum iterations, the maximum number of modes, etc.) were maintained. Decompositions (using the ICEEMDAN approach) were carried out under the MATLAB programming environment. Commensurate with the extant literature [31, 32, 34], a flowchart of the ICEEMDAN decomposition technique is presented in Figure 1.

3.2. Rényi Transfer Entropy. The generic information theory [90] results in transfer entropy (TE). The theory uses an algorithm to calculate the quota of symbolic series that may occur in a given probability distribution [43, 91]. Contemporary works on TE are based on Shannon's [92] arithmetical communication theory as an uncertainty measure, which is derived from information theory.

For a probability distribution with different symbols of a specific experiment $P_{j}$, the mean information for a symbol is defined as

$$
H=\sum_{j=1}^{n} P_{j} \log _{2}\left(\frac{1}{P_{j}}\right)
$$

where $n$ signifies the quota of different symbols related to $p_{j}$ probabilities [90]. The mean quota of bits essential to optimally encode independent draws [91] may be approximated using the Shannon [92] framework (hereafter termed as Shannon entropy (SE)) for a discrete random variable $J$ with $p(j)$ probabilities.

$$
H_{J}=-\sum_{j=1}^{n} p(j) \log _{2} p(j)
$$

The Kullback and Leibler [93] distance (KLD) model is used in quantifying the flow of information between twotime series procedures under the SE framework given that two-time series procedures are Markov. $I$ and $J$ are provided as two discrete random variables with equivalent marginal probabilities of $p(i)$ and $p(j)$, as well as a joint probability of $p(i, j)$, and a dynamic stationary Markov process of order $k$ (process $I$ ) and $I$ (process $J$ ). The Markov property states that the probability of observing $I$ in state $i$ at time $t+1$ conditional on $k$ prior observations is $p\left(i_{t+1} \mid i_{t}, \ldots, i_{t-k+1}\right)=\left(i_{t+1} \mid i_{t}, \ldots, i_{t-k}\right)$. The average quota of bits required to encode the observation at $t+1$ before $k$ values are known may be expressed as

$$
h_{j}(k)=-\sum_{i} p\left(i_{t+1}, i_{t}^{(k)}\right) \log _{2} p\left(i_{t+1} \mid i_{t}^{(k)}\right)
$$

where $i_{t}^{(k)}=\left(i_{t}, \ldots, i_{t-k+1}\right)$ (analogously for procedure $\left.J\right)$. The flow of information to process $I$ from process $J$ is assessed in a bivariate scenario by measuring the variation from the generic Markov property $p\left(i_{t+1} \mid i_{t}^{(k)}\right)$ $=p\left(i_{t+1} \mid i_{t}^{(k)}, j_{t}^{(I)}\right)$, which is based on the KLD. The Shannon transfer entropy is then expressed as follows:

$$
T_{J \longrightarrow I}(k, l)=\sum P\left(i_{t+1}, i_{t}^{(k)}, j_{t}^{(I)}\right) \log \frac{P\left(i_{t+1} \mid i_{t}^{(k)}, j_{t}^{(I)}\right)}{P\left(i_{t+1} \mid i_{t}^{(k)}\right)},
$$

where $T_{J \longrightarrow I}$ estimates the information flow from $J$ to $I$. Then, again, information flow from $I$ to $J, T_{J \longrightarrow I}$, can be derived. The net information flow, which is determined as the difference between $T_{J \longrightarrow I}$ and $T_{J \longrightarrow I}$, is the fundamental path of information flow.

Despite its usefulness in finance, the SE does not provide equal weight to all possible outcomes in a probability distribution. Fat tails, which are ubiquitous in asset pricing and returns, are not taken into account by this assumption. Notwithstanding, employing a weighting value $q$, the Rényi [94] transfer entropy (RTE) overcomes the issue. The RTE may be calculated using the formula

$$
H_{J}^{q}=\frac{1}{1-q} \log _{2} \sum_{j} P^{q}(j)
$$

with $q>0$. For $q \longrightarrow 1$, RE converges to SE. For $0<q<1$, thus, events with a low probability are given more weight, while for $q>1$ the weights favour outcomes $j$ with a higher initial probability. As a consequence, depending on parameter $q$, RTE allows for varied priorities to be offered to different regions of the distribution [41, 91]. This, unlike SE, is a desirable feature of RTE's application in finance.

Moreover, with the escort distribution, $\varnothing_{q}(j)=p^{q}(j) / \sum_{j} p^{q}(j)$ for $q>0$ to normalise the weighted distributions [95], $\mathrm{RE}$ is derived as

$$
R T_{J \longrightarrow I}(k, l)=\frac{1}{1-q} p\left(i_{t+1}, i_{t}^{(k)}, j_{t}^{(I)}\right) \log _{2} \frac{\sum_{i} \varnothing_{q}\left(i_{t}^{(k)}\right) P^{q}\left(i_{t+1} \mid i_{t}^{(k)}\right)}{\sum_{i, j} \varnothing_{q}\left(i_{t}^{(k)}, j_{t}^{(I)}\right) P^{q}\left(i_{t+1} \mid i_{t}^{(k)}, j_{t}^{(I)}\right)}
$$

Note that the RTE calculation might yield negative estimates. Noting the history of $J$, in this case, suggests significantly extra uncertainty compared to noting the history of $I$ only would imply. Negative numbers imply higher risks in the context of our study, whereas positive ones suggest fewer risks.
Transfer entropy estimations are prone to bias in small samples [96]. The effective transfer entropy (ETE) could correct this and may be calculated as follows:

$$
\operatorname{ETE}_{J, I}(k, l)=T_{J, I}(k, l)-T_{\text {Jshuffled, } I}(k, l),
$$




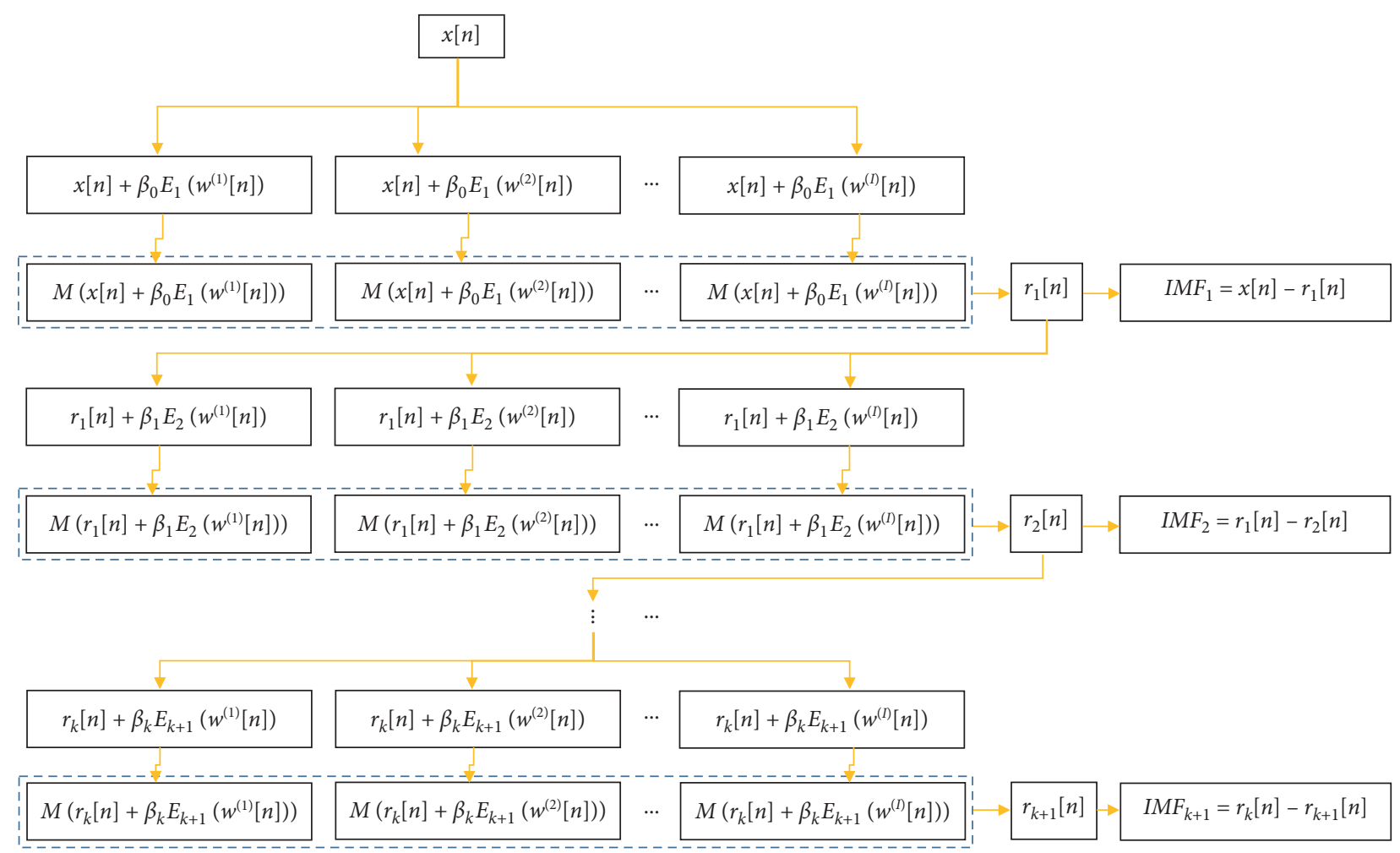

FIgURE 1: Flowchart of the ICEEMDAN algorithm [34].

where the transfer entropy using stumbled forms of the time series $J$ is denoted by $T_{\text {Jshuffled } \longrightarrow I}(k, l)$. The procedure removes the time series serial dependence of $J$ while retaining the statistical dependence between $J$ and $I$ by repeating random draws from the observed time series $J$ and realigning them to form a new time series. This causes $T_{\text {Jshuffled } \longrightarrow I}(k, l)$ to converge to zero as the sample size grows, and any nonzero value of $T_{J \text { shuffled } \rightarrow I}(k, l)$ is caused by small sample effects. As a consequence, recurring shuffles and the mean of the shuffled transfer entropy approximations across all repetitions may be used as a small sample bias estimator. To get bias-corrected effective transfer entropy estimates, they are deducted from the RE estimations.

The Markov block bootstrap approach may be used to establish the statistical significance of transfer entropy estimations. Unlike shuffling, this keeps the dependencies inside variables $J$ and $I$ but removes the statistical dependencies between them. As a result, per the null hypothesis of no information flow, bootstrapping produces a distribution of transfer entropy estimates that may be examined. $1-\widehat{q} \mathrm{~T}$ yields the related $p$ value where $\widehat{q}$ T specifies the quantile of the simulated distribution generated by the relevant transfer entropy estimations (see $[8,91]$ ).

Finally, because transfer entropy techniques were designed to cope with discrete data, the framework's continuous data must be discretised. This is accomplished by dividing the data series into a finite quota of bins, a technique known as symbolic encoding $[8,91]$. The emblematically encoded time series (i.e., discrete) for a quota of bins $n$ and bounds $q_{1}, q_{2}, q_{3}, \ldots, q_{n-1} \quad\left(q_{1}<q_{2}<q_{3}<\right.$ $\left.\ldots<q_{n-1}\right)$ and continuous observed time-series data $y_{t}$ may be represented as

$$
S_{t}= \begin{cases}1, & y_{t} \leq q_{1}, \\ 2, & q_{1}<y_{t}<q_{2}, \\ & \vdots \\ n-1, & q_{n-2}<y_{t}<q_{n-1}, \\ n, & y_{t} \geq q_{n-1} .\end{cases}
$$

When choosing the number of bins, the magnitude and distribution of the studied time series must be noted. Because tail data is crucial, binning is usually based on pragmatic quantiles of the left and right tails. Using the empirical quantiles of 0.05 and 0.95 as the lower and upper bounds of the bins, this is easily achieved. As a result, there are three symbolic encodings: negative extreme returns (lower tail) are in the first bin (0.05), positive extreme returns (upper tail) are in the third bin (0.95), and normal returns are in the second bin (intermediate, 0.90). Using the chain rule on the emblematic encoding, conditional probabilities may be expressed as proportions of joint probability. Consequently, the probabilities in Equations (7) and (9) may be calculated using the relative frequencies of all likely realisations.

\section{Data and Preliminary Analysis}

The daily stock market indices for 17 key Islamic markets across the Middle East (Bahrain, Egypt, Iraq, Jordan, Kuwait, 
Oman, Palestine, Qatar, Saudi Arabia, and UAE), Africa (Morocco), and Asia and Pacific (Bangladesh, India, Indonesia, Kazakhstan, Malaysia, and Pakistan), as well as G7 stock markets (Canada, France, Germany, Italy, Japan, the UK, and USA) and key NASDAQ global indices (global market composite index (GMI), Europe index (EUMI), emerging markets index (EMI), developed markets index (DMI), and BRIC index (BMI)), were utilised in the study. The data set spanned between 22 January 2020 and 08 September 2021. The daily stock indices were extracted from EquityRT (https://www.equityrt.com/) and the worldwide cases of confirmed COVID-19 cases per day were retrieved from OWID (https://raw.githubusercontent.com/owid/ covid-19-data/master/public/data/owid-covid-data.xlsx).

The inclusion of the key global indices is to cater for the section of the conventional equities which is not represented by the sampled markets. A few of the chosen indices overlap because some of them are subsets of others. This is useful for determining COVID-19's overall and dispersed impact on equities markets. The log-returns of the daily stock indices were computed as $r_{t}=\log \left(P_{t}\right)-\log \left(P_{t-1}\right)$, where $r_{t}$ is the return from period $t-1$ to $t$ and $P_{t-1}$ and $P_{t}$ are data points at the respective periods $t-1$ and $t$.

To enable comparison, the study maintained a balanced set for estimations by matching all data series by date.

A trajectory of the data used in the study is presented in Figure 2, with the descriptive summary in Table 1 . The purpose is to offer an overview of the trend of the studied equities markets over the COVID-19 pandemic period.

It could be seen from Figure 2 that, in the initial periods of the COVID-19 pandemic, which was rapidly escalating in terms of confirmed cases, all of the indices appeared to have a severe negative trend. While COVID-19 verified cases have continued to climb to this day, the markets have been more stable, with rising inclinations evident since certain countries went under lockdown in early February 2020. In the early days of October 2020, the markets began to plummet again when most countries began to ease lockdown rules and overseas travel recommenced gradually. This contributed to a second wave of the virus approaching the Christmas season, as Owusu Junior et al. [8] and Salyer et al. [97] also report. Markets, on the other hand, have been trending higher since December 2020 (the start of the Christmas season), as fears of a second wave faded. The indices' negative trend shows investors' and the economy's reaction to apocalyptic events such as pandemics. This observation ignites the findings of Sander et al. [98]. The unfavourable correlation between epidemics and financial markets is intuitive and comprehensible.

A glance at the descriptive summary of the return series in Table 1 reveals numerous noteworthy aspects of the stock market return rates under consideration. Throughout the studied period, except for Bahrain, Egypt, Indonesia, and Oman, all other indices had positive averages. The negative skewness statistics for all markets except Bangladesh, Kazakhstan, Malaysia, Saudi Arabia, France, Germany, and Japan show that, in the COVID-19 era, bigger losses outnumber larger earnings in all other equities markets under consideration. Whereas the G7 markets (France, Germany, and Japan) might have put in place some stringent measures against the pandemic to ensure the positive skewness, the case for the Islamic markets (Bangladesh, Kazakhstan, Malaysia, and Saudi Arabia) might result from the fundamental nature of the market to resist some form of shocks during crises. The descriptive summary also suggests that, except for Japan, all of the return series' kurtosis statistics showed excess kurtosis. In comparison to a normal distribution, this suggests that the returns have a lot of tails. As it is a stylised fact about financial time series [99], this observation is hardly surprising.

\section{Empirical Results}

The fundamental objective of this study is addressed in this section. For each effective transfer entropy (ETE), the results from both Shannon ETE and Rényi ETE are presented to prove the relative desirability of Rényi ETE. The information flow from COVID-19 to the equities markets under study is analysed. The study focuses on the one-way flow from COVID-19 to the equities markets because stocks cannot influence COVID-19 cases. The RE technique produces ETEs that are both negative (high risk) and positive (low risk). Diversification is enabled by pairing negative receiving ETEs equities with positive receivers. A fault weight of 0.30 is adopted to account for fat tails in the return series, which corresponds to the stylised fact about financial time series. The study also presents the results in the frequency domain and at the composite level. In the latter, IMFs 1-5 and Residual are utilised to indicate intrinsic times of short-, intermediate-, and long-term dynamics, with the residual reflecting the long-term trajectory, which reveals the underlying character of the relevant series. Evaluations of the markets' dynamic response to the COVID-19 pandemic are made using the time scales.

ETEs are shown by black points within blue bars. They are presented at both the composite and the frequencydomain states. The $95 \%$ confidence bounds are indicated at the ends of the blue bars. As a result, a rejection of the null hypothesis of "no information flow" holds if these confidence boundaries are in either the positive or negative sections. Information flow is insignificant if there is any overlap at the origin.

5.1. Rényi ETEs Analysis. Observations made from Figure 3 reveal both positive and negative directions of information transfer (ETEs) from COVID-19 to the studied Islamic and conventional equities markets. Specifically, at the composite state, the study finds a negative information transfer from COVID-19 to the equities markets in Bahrain, Indonesia, Kazakhstan, Kuwait, Morocco, Pakistan, Palestine, Qatar, Saudi Arabia, and USA but positive one in all other markets. Notably, from the global indices studied, the emerging markets index (EMI) also showed that it is positively affected by COVID-19 related information flow. This is not surprising because most of the individual markets found to be negatively impacted by COVID-19 ETEs are classified as emerging. Thus, the aggregate impact is supported by the 


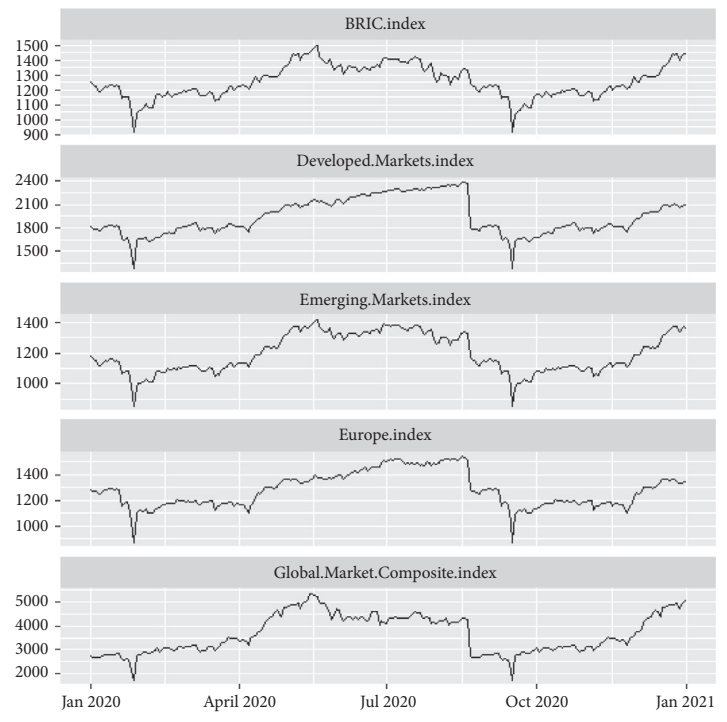

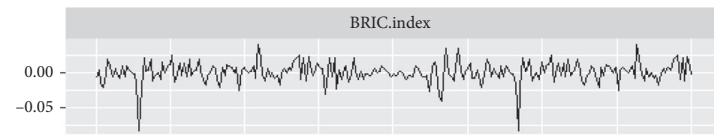

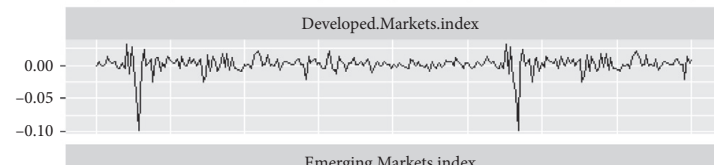

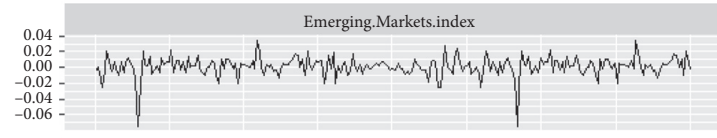

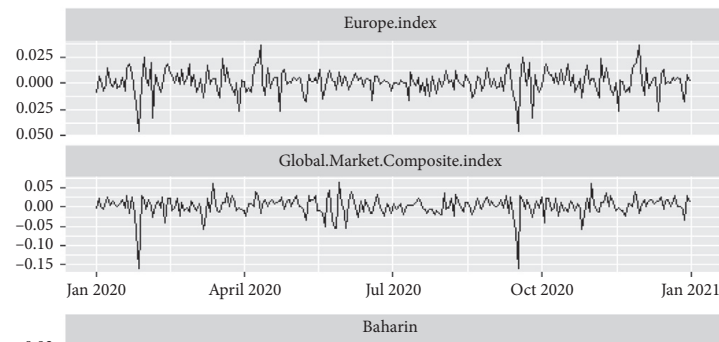
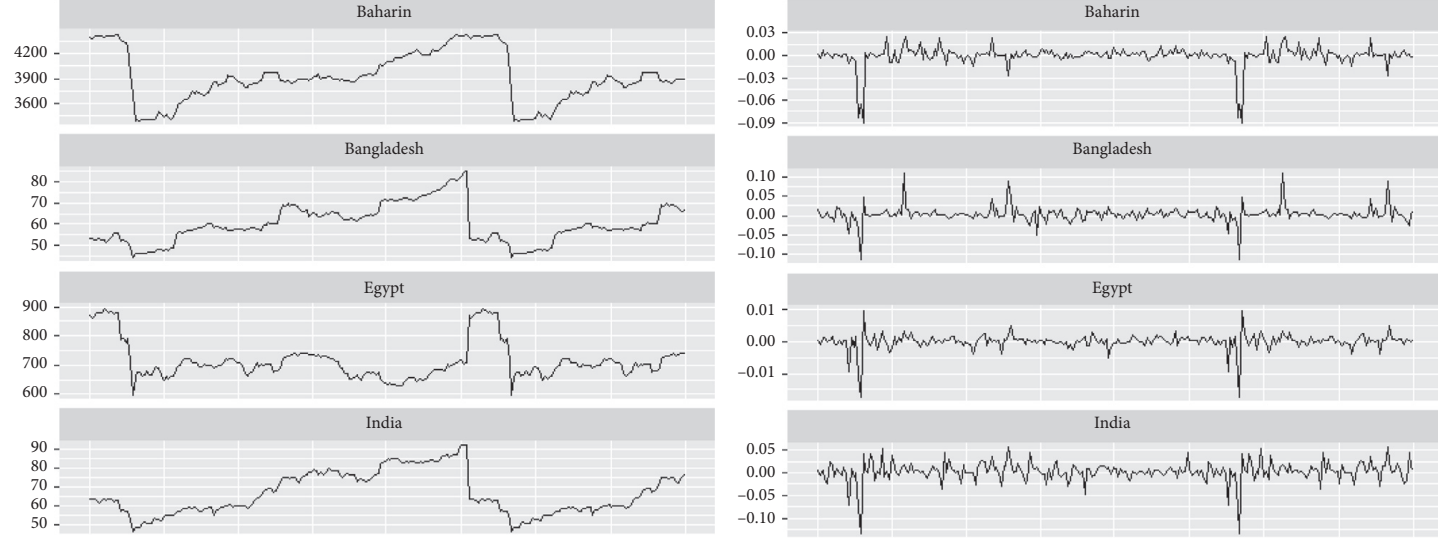
$-0.09-$

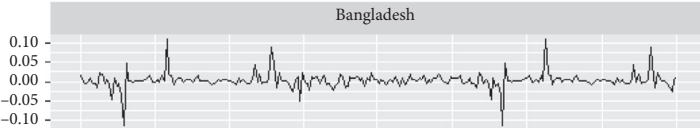
-0.05 - w 0.01
0.00
-0.01
0.05
0.00
-0.05
$-0.10-$
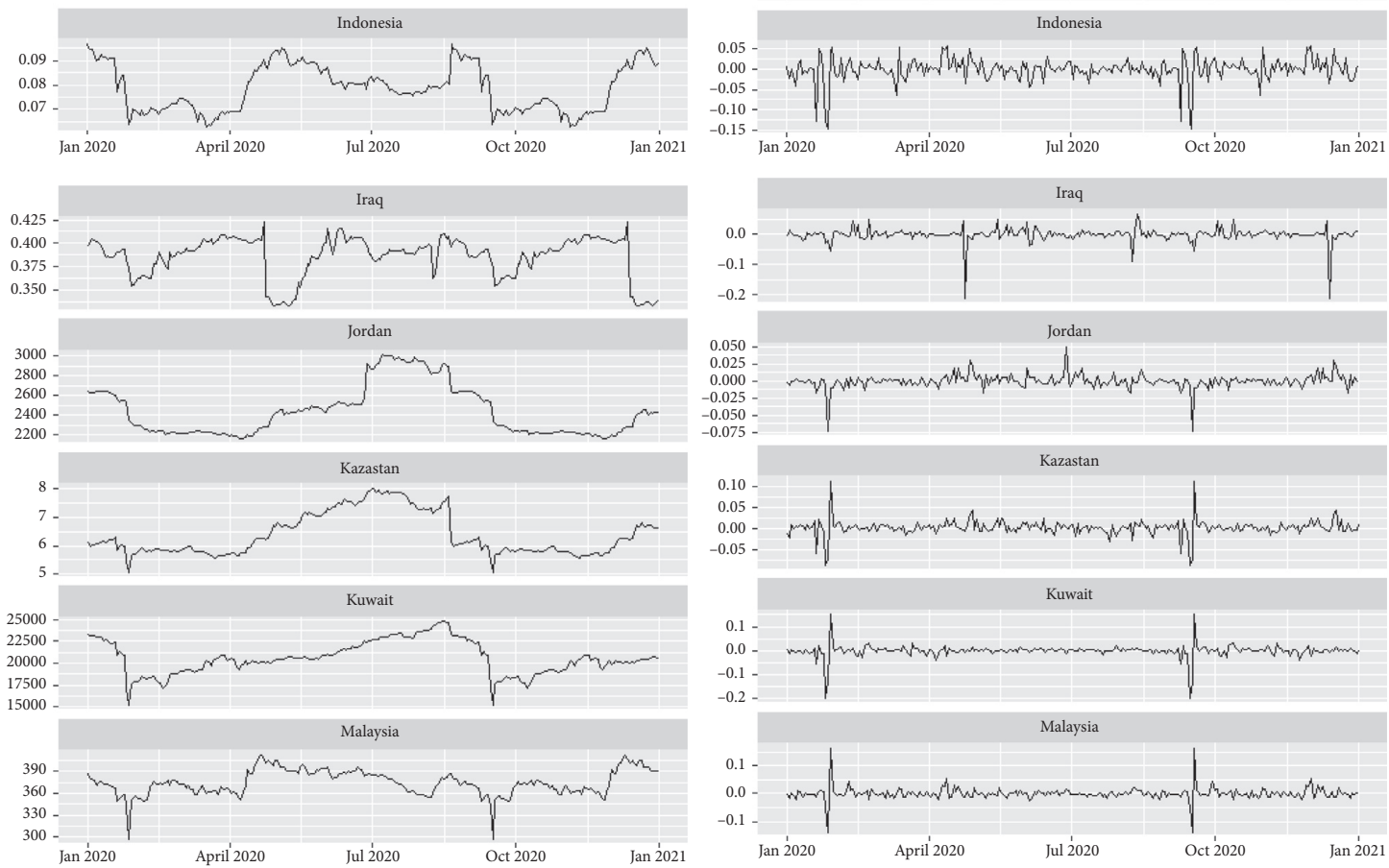

(a)

FIgURE 2: Continued. 

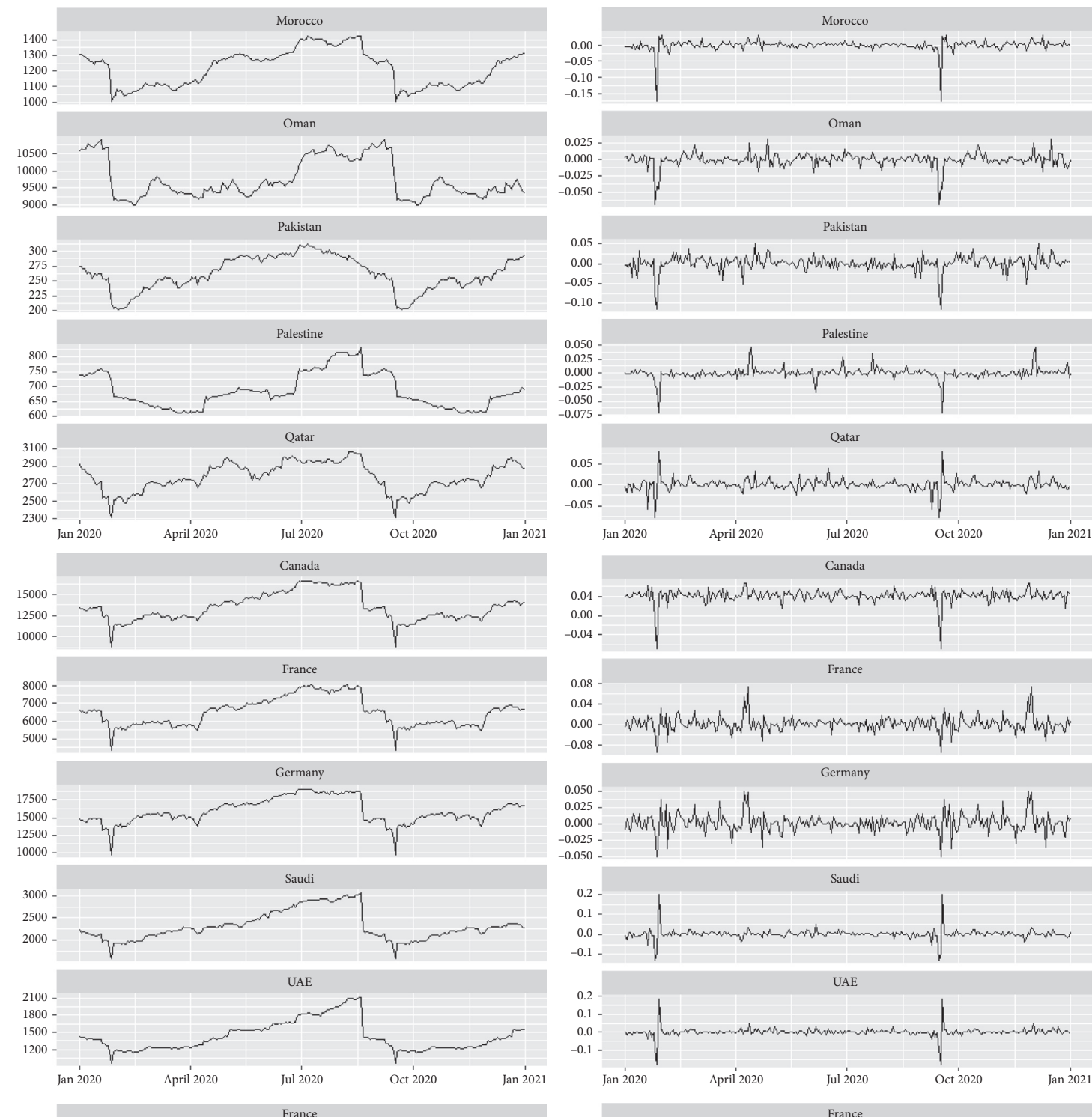

Germany
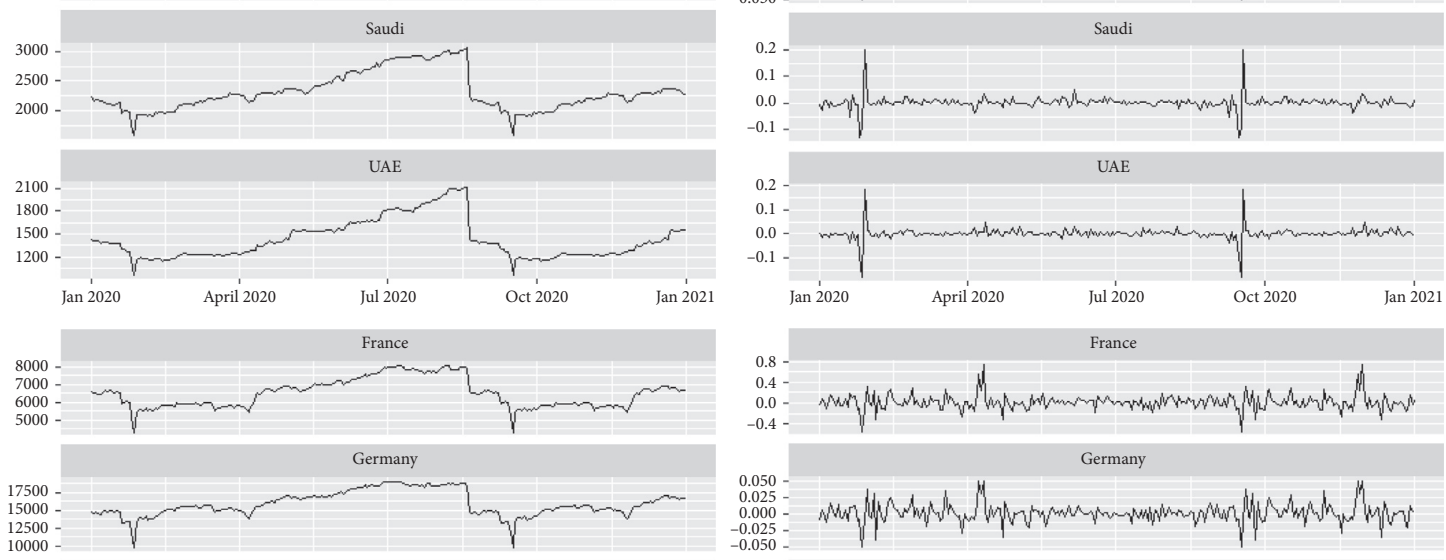

$0.4-$
$0.0-$
$-0.4-$

$0.050-$
$0.025-$
$0.000-$
$-0.025-$
$-0.050-$
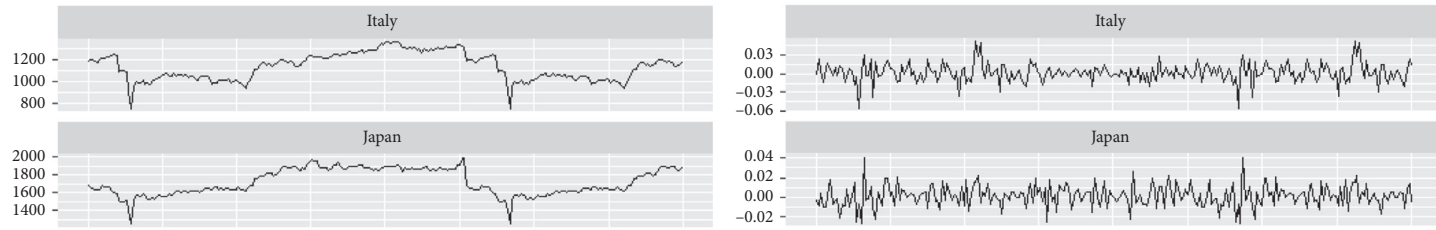
$-0.03-$
$-0.06-$

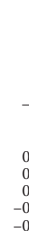

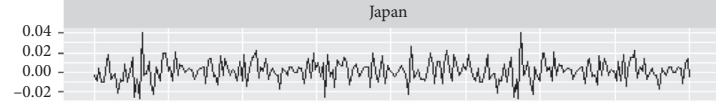
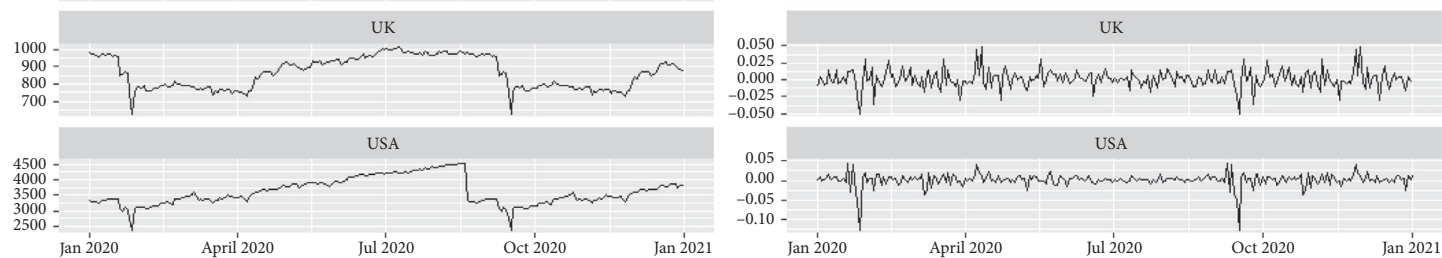

(b)

Figure 2: Continued. 


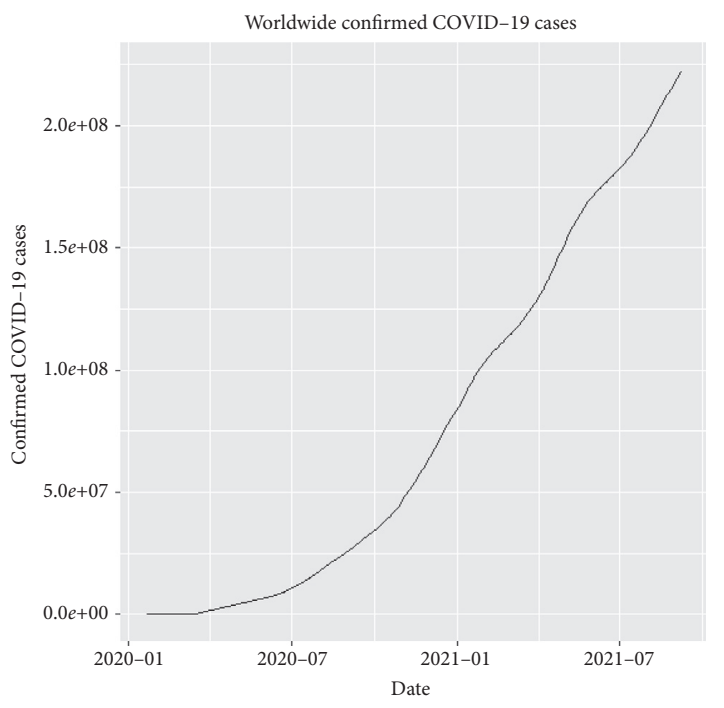

(c)

FIgURE 2: Time-series plot of selected equities and worldwide daily COVID-19 cases.

TABle 1: Descriptive summary of selected equities and worldwide daily COVID-19 cases.

\begin{tabular}{|c|c|c|c|c|c|c|}
\hline Market/Country & Minimum & Maximum & Mean & $\mathrm{SD}^{1}$ & Skewness & Kurtosis $^{2}$ \\
\hline COVID-19 & 0.0016 & 0.6449 & 0.0210 & 0.0643 & 6.9417 & 57.3324 \\
\hline BMI & -0.0816 & 0.0412 & 0.0010 & 0.0142 & -1.2007 & 6.7322 \\
\hline DMI & -0.0979 & 0.0310 & 0.0011 & 0.0121 & -3.5675 & 26.9884 \\
\hline EMI & -0.0745 & 0.0350 & 0.0012 & 0.0118 & -1.6174 & 9.7779 \\
\hline EUMI & -0.0460 & 0.0361 & 0.0012 & 0.0104 & -0.6554 & 3.1193 \\
\hline GMI & -0.1579 & 0.0648 & 0.0013 & 0.0244 & -1.9008 & 10.5126 \\
\hline Bahrain & -0.0901 & 0.0258 & -0.0002 & 0.0129 & -4.4150 & 26.9924 \\
\hline Bangladesh & -0.1133 & 0.1084 & 0.0029 & 0.0190 & 0.1284 & 15.9887 \\
\hline Egypt & -0.1721 & 0.0959 & -0.0009 & 0.0236 & -2.8934 & 20.8358 \\
\hline India & -0.1350 & 0.0560 & 0.0023 & 0.0212 & -2.0487 & 12.0509 \\
\hline Indonesia & -0.1463 & 0.0582 & -0.0011 & 0.0273 & -1.9717 & 9.2137 \\
\hline Iraq & -0.2099 & 0.0685 & 0.0001 & 0.0236 & -4.4003 & 38.7612 \\
\hline Jordan & -0.0745 & 0.0495 & 0.0001 & 0.0102 & -1.5086 & 19.6118 \\
\hline Kazakhstan & -0.0878 & 0.1120 & 0.0011 & 0.0173 & 0.0788 & 16.2467 \\
\hline Kuwait & -0.1994 & 0.1511 & 0.0000 & 0.0249 & -2.7185 & 36.0605 \\
\hline Malaysia & -0.1380 & 0.1640 & 0.0004 & 0.0210 & 1.2912 & 32.8132 \\
\hline Morocco & -0.1732 & 0.0326 & 0.0000 & 0.0165 & -7.2407 & 74.3607 \\
\hline Oman & -0.0695 & 0.0317 & -0.0002 & 0.0103 & -2.5260 & 15.1852 \\
\hline Pakistan & -0.1137 & 0.0511 & 0.0000 & 0.0179 & -2.0049 & 11.1341 \\
\hline Palestine & -0.0714 & 0.0461 & 0.0002 & 0.0101 & -1.3920 & 19.0652 \\
\hline Qatar & -0.0777 & 0.0800 & 0.0007 & 0.0139 & -0.1814 & 13.4451 \\
\hline Saudi Arabia & -0.1307 & 0.1979 & 0.0018 & 0.0235 & 2.0823 & 36.2245 \\
\hline UAE & -0.1771 & 0.1847 & 0.0016 & 0.0241 & -0.1186 & 38.9031 \\
\hline Canada & -0.1086 & 0.0281 & 0.0010 & 0.0131 & -3.9400 & 30.1531 \\
\hline France & -0.0545 & 0.0740 & 0.0018 & 0.0136 & 0.7561 & 6.6918 \\
\hline Germany & -0.0498 & 0.0507 & 0.0016 & 0.0131 & 0.2033 & 3.5240 \\
\hline Italy & -0.0552 & 0.0522 & 0.0016 & 0.0138 & -0.0261 & 2.8226 \\
\hline Japan & -0.0275 & 0.0409 & 0.0016 & 0.0110 & 0.0840 & 0.5407 \\
\hline UK & -0.0503 & 0.0483 & 0.0014 & 0.0127 & -0.0066 & 2.9953 \\
\hline USA & -0.1277 & 0.0450 & 0.0011 & 0.0159 & -3.4210 & 26.1524 \\
\hline
\end{tabular}

individual impacts. These negative impacts signify that the equities markets are characterised by high risk. However, it is important to note that all the composite ETEs lack statistical significance.
Turning to the frequency-domain ETEs, the study finds that, except for Japan, Pakistan, Qatar, and UAE, all ETEs at IMF1 are negative and statistically nonsignificant. This is an indication that, in the early days of the pandemic, several 

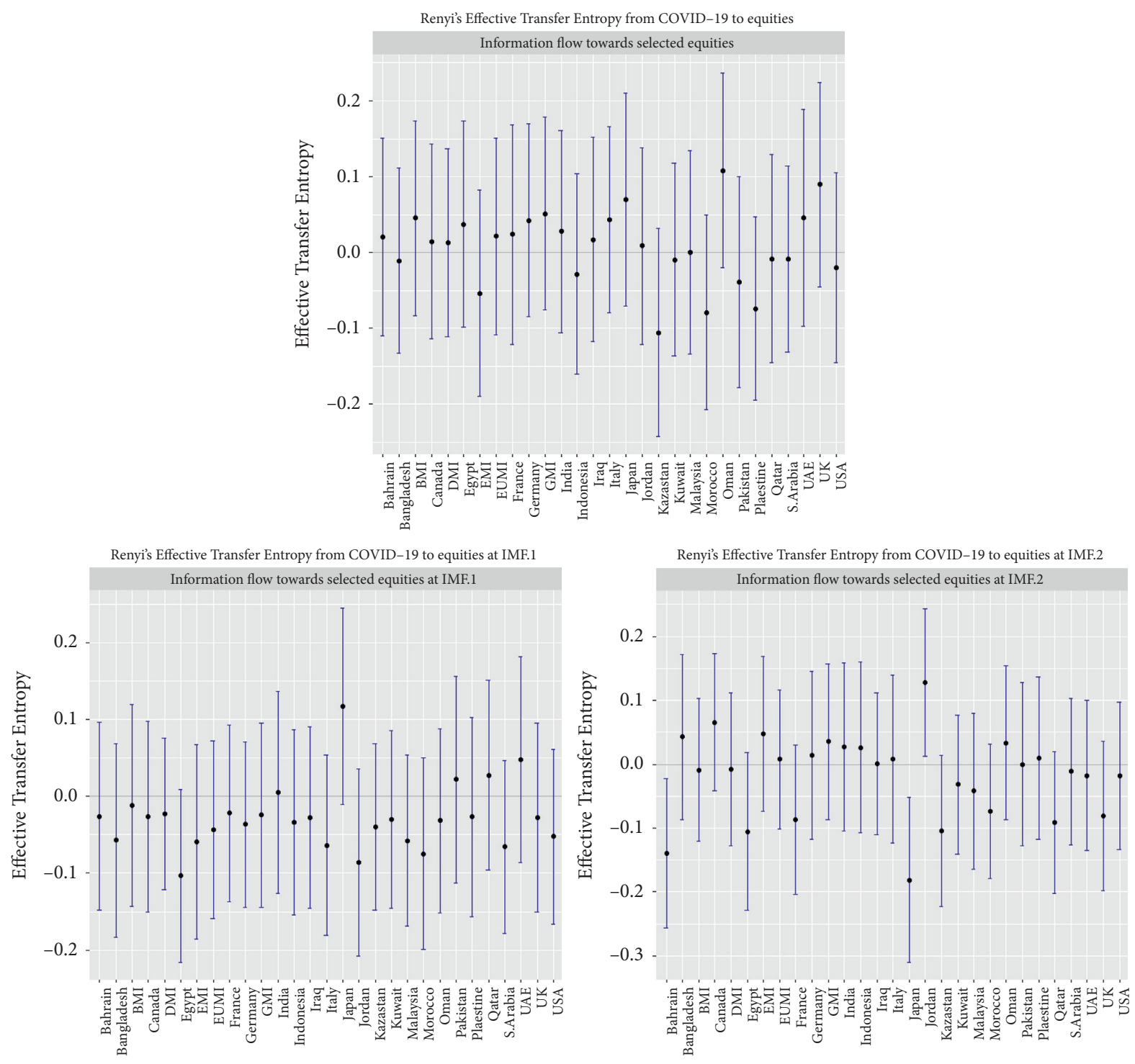

(a)

Figure 3: Continued. 

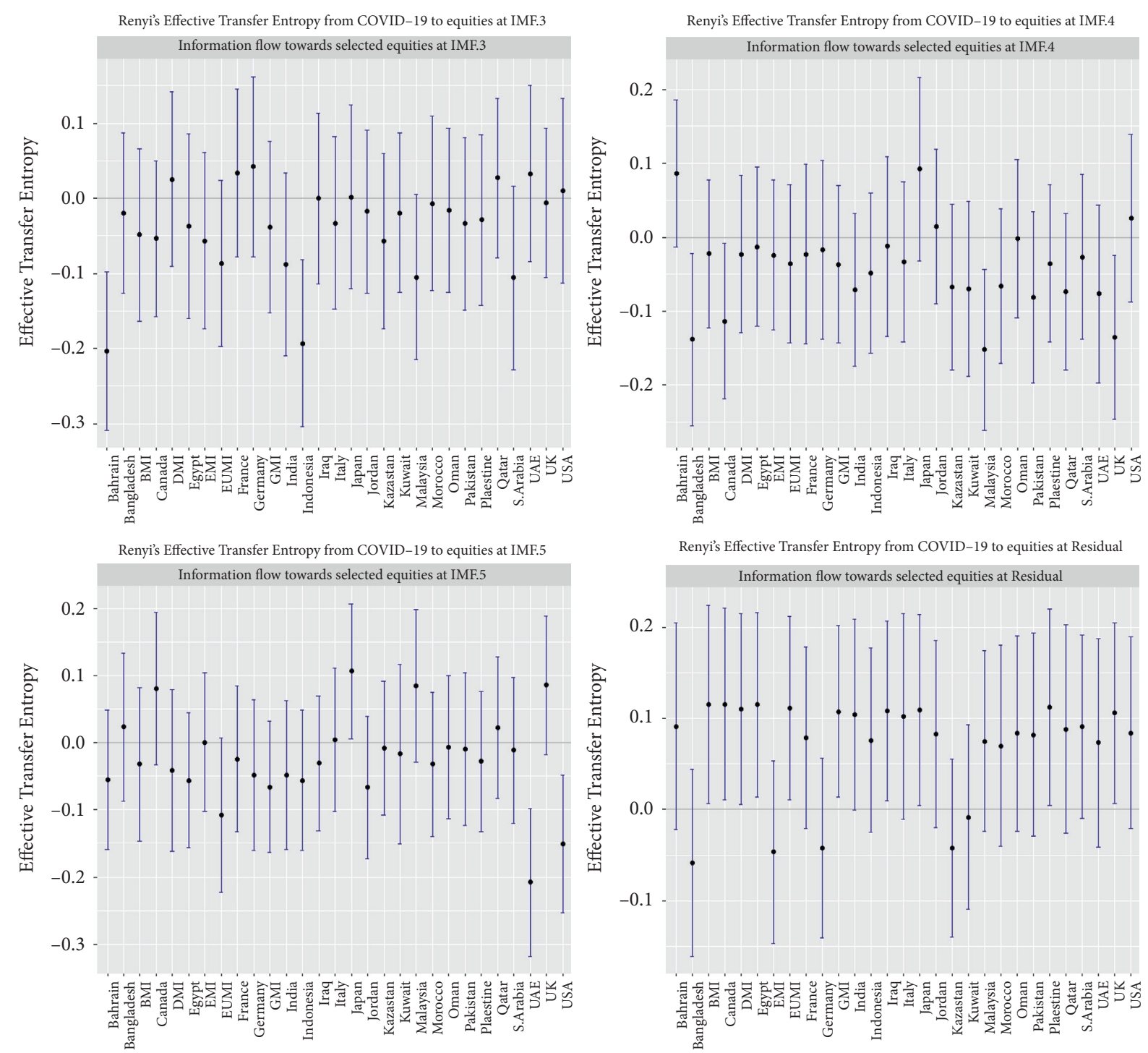

(b)

Figure 3: Composite and frequency-domain Rényi ETEs from COVID-19.

Islamic and conventional equities markets were negatively affected by information flow from COVID-19. After a short while in the early periods of the pandemic, equities markets strategised and this saw a few markets responding positively to the pandemic, as IMF2 depicts. More importantly, three ETEs, Bahrain (negative), Japan (negative), and Jordan (positive), proved to be statistically significant, suggesting that equities from Bahrain and Japan are highly risky owing to COVID-19, whereas equities from Jordan have relatively low risk due to COVID-19. Intuitively, possible diversification opportunities are provided by these stocks in the short run, with two possible combinations: (i) Jordan and Bahrain and (ii) Jordan and Japan. These combinations would result in minimising (maximising) portfolio risk (returns) in the COVID-19 era. These are the only diversification opportunities in the short term between the studied Islamic and conventional equities. At IMF3, several negative and positive receiving ETEs are spotted with the only significant ETEs being Bahrain and Indonesia, both of which are negative (highly risky). This finding is not far from that of Abdullahi [14] who revealed that Islamic markets have also been constrained by the COVID-19 pandemic. This observation also rests well with the projections of S\&P Global [15] concerning IFMs.

The number of negative receiving ETEs increases across the time horizon. At IMF4, Bahrain, Canada, Malaysia, and the UK are found to be negatively affected by the pandemic's information flow, which means that COVID-19 creates high risks for these markets in the mid-term. The study reveals another diversification opportunity between Islamic and conventional equities at IMF5, where UAE and USA are negative (highly risky) ETE recipients and Japan is a positive (low risk) ETE recipient. The only two possible combinations for the intermediate term presented include (i) Japan and UAE and (ii) Japan and USA. The long term presents different dynamics where, at the residual level, the majority 
TABLE 2: Summary of diversification prospects from Islamic and conventional equities.

\begin{tabular}{|c|c|c|c|c|}
\hline \multirow{2}{*}{ Data series } & \multirow{2}{*}{ Time scale } & \multicolumn{2}{|c|}{ Diversification prospect? } & \multirow{2}{*}{ Compatible equities (Rényi) } \\
\hline & & Rényi & Shannon & \\
\hline Composite & Nil & $x$ & $x$ & Nil \\
\hline IMF1 & Short-term & $x$ & $x$ & Nil \\
\hline IMF2 & Short-term & $\checkmark$ & $x$ & Jordan versus Bahrain; Jordan versus Japan \\
\hline IMF3 & Short-term & $x$ & $x$ & Nil \\
\hline IMF4 & Mid-term & $x$ & $x$ & Nil \\
\hline IMF5 & Mid-term & $\checkmark$ & $x$ & Japan versus UAE; Japan versus USA \\
\hline IMF Residual & Long-term & $x$ & $x$ & Nil \\
\hline
\end{tabular}
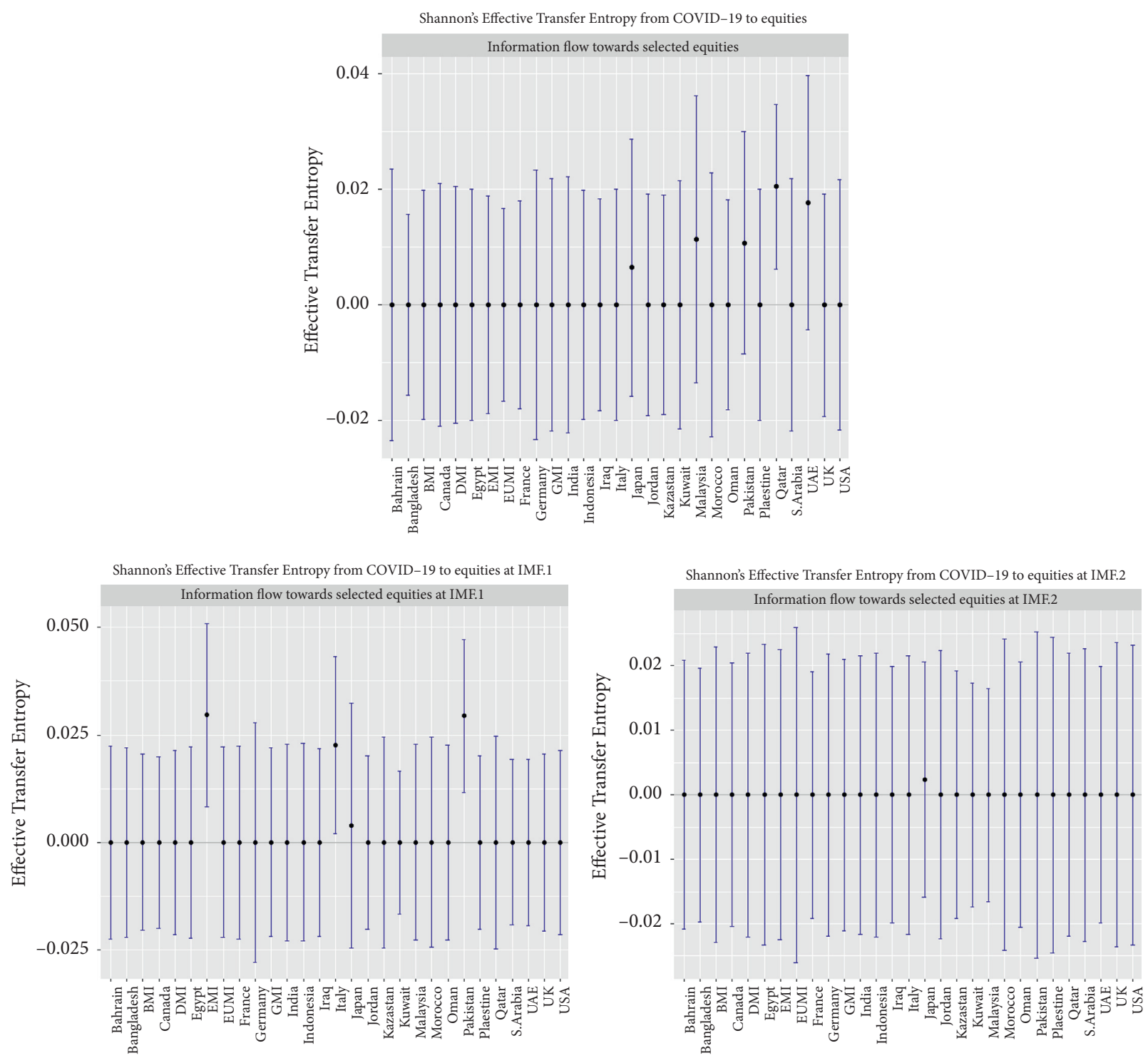

(a)

FIgURE 4: Continued. 

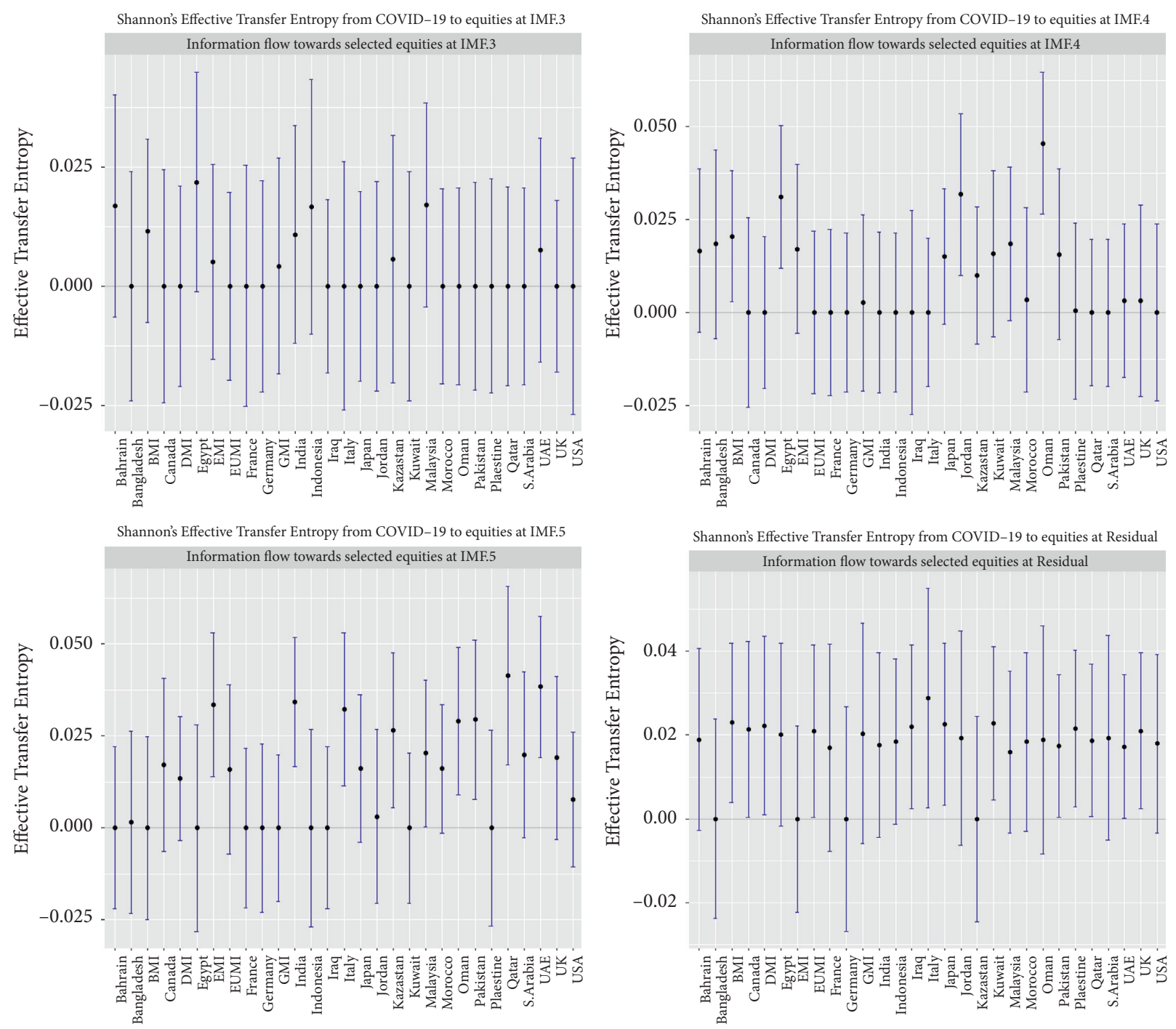

(b)

FIgURE 4: Composite and frequency-domain Shannon ETEs from COVID-19.

of the ETEs are positive, suggesting that the markets are about to get saturated with COVID-19 information flow. Bangladesh, the emerging markets index, Germany, Kazakhstan, and Kuwait were found to be negative ETE recipients in the long run. No significant diversification opportunities for the studied Islamic and conventional markets are found in the long run. A summary of the significant diversification opportunities and the plausible combinations for Rényi and Shannon ETEs is presented in Table 2 .

5.2. Shannon ETEs. The Shannon ETE results (see Figure 4), taken as a whole, support the Rényi ETE's efficiency. It is worth noting that the Shannon ETE gives the tails of the return distribution equal weights. As a result, it is not surprising that the findings contradict the stylised realities of asset returns. The results in Figure 4 show that COVID-19 has no substantial negative transfer entropies to the studied
Islamic and conventional equities. Only positive information flows are documented when their significance is proven. Regardless of the investment horizon, the Shannon ETEs imply only significantly high risks for equities. They also imply that there is no prospect for diversification within the collection of Islamic and conventional equities classes.

Wholistically, under the Shannon ETEs, the study discovers no equity market (except for Qatar) as a significant recipient of ETEs at the composite level. With increasing frequency, the number of significant ETEs tends to increase. In the long run, there exist significant ETEs to some equities markets. These findings confirm the $\mathrm{CMH}, \mathrm{HMH}$, and AME in general. They do not, however, agree with the $\mathrm{EMH}$ in that the COVID-19 pandemic is yet to cause all markets to react in the same way across all investment horizons. Moreover, the Rényi and Shannon entropies are found to converge in the long run, and both validate the $\mathrm{CMH}, \mathrm{HMH}$, and $\mathrm{AMH}$. The studied Islamic and conventional markets have yet to stop reacting to the COVID-19 information flow, which 
suggests that the fundamental market dynamics are yet to be reverted to. Table 2 also presents an overview of the Shannon entropy results.

The findings divulge some portfolio diversification potentials in the short and intermediate terms, with none in the long term. The study defines IMFs 1-3 to represent shortterm dynamics, IMFs 4 and 5 to represent intermediate-term dynamics, and IMF Residual to represent long-run dynamics, per the extant literature such as Bouoiyour et al. [100], Bouoiyour et al. [101], Owusu Junior et al. [102] Owusu Junior et al. [3], Owusu Junior et al. [103], Owusu Junior and Tweneboah [76], and Yang et al. [85]. Investor attitudes and market dynamics characterise the short term; the influence of significant events characterises the intermediate period; fundamental features characterise the long term [85]. The findings, in keeping with these delineations, show prospects of diversification across the short and intermediate terms, between either Jordan and Bahrain and Jordan and Japan or Japan and UAE and Japan and USA, for the respective time scales.

The findings, which suggest time- and frequency-dependent diversification opportunities between the studied equities, corroborate the conclusions made by the extant literature using wavelet analysis $[60,66-68]$ and transfer entropies $[8,25]$, although different variables were employed in different contexts.

On the premise that structural changes drive the creation of new markets, which brings about time-dependent market efficiencies, the findings corroborate the principles of Lo's [51] adaptive market hypothesis (AMH). This is evidenced by the positive and negative transfer entropies (ETEs) that vary over time horizons. Additionally, according to the heterogeneous market hypothesis (HMH) engineered by Müller et al. [52], investors analyse their risk and return preferences in making investment decisions over various time scales, after considering historical and present news items. This suggests that the variations in the direction and significance of ETEs for the Islamic and conventional equities studied also reflect Müller et al.'s [52] HMH. It is intuitive to note that the findings rekindle the competitive market hypothesis [8], which advances that, during volatile market times like the COVID-19 pandemic, information flow and spillovers across assets and/ or asset classes accelerate for rational, yet irrational investors' never-ending pursuit for competitive rewards and risks to achieve portfolio goals. Within the short and intermediate terms, the varying ETEs revealed present shaking evidence in support of the efficient market hypothesis of Fama [45, 46].

\section{Conclusions}

The study investigated the effect of COVID-19 information flow on Islamic and conventional equities returns to assess whether the information flow from COVID-19 leaves behind safe haven, diversification, or hedging prospects for global equities investors. The study addressed three main questions: (i) Are there differences in the way Islamic and conventional equities respond to information flow from COVID-19? (ii) Are there diversification prospects for Islamic and conventional equities in the post-COVID-19 era? (iii) At what time scale(s) could diversification be achieved? A total of 29 daily stock market indices made up of $17 \mathrm{key}$ Islamic markets across the Middle East (10), Africa (1), and Asia and Pacific (7); G7 stock markets; and 5 key NASDAQ global indices were employed in the study. The data set spanned between 22 January 2020 and 08 September 2021.

First, the ICEEMDAN approach was used to decompose the return series of the 29 stock market indices into intrinsic periods, which represent the short-, intermediate-, and longterm horizons. This aided in understanding the dynamic nature of investors' responses to the pandemic while also reducing noise in the series. This strategy is commensurate with the $\mathrm{AMH}, \mathrm{CMH}$, and $\mathrm{HMH}$, all of which are opposed to the EMH. Second, the Rényi transfer entropy (RTE) was used on compound series and their associated frequency domains to measure information flow from COVID-19 to equities markets. A fault weight of 0.30 was specified to cater for fat tails in stock returns. In the middle of the COVID-19 pandemic, Rényi transfer entropy accommodates for fat tails in equity returns while discriminating between high-risk (negative ETEs) and low-risk (positive ETEs) equities. For comparison and to prove RTE's efficiency over the Shannon entropy (SE), the ETEs for SE were also reported.

The results show a few substantial differences in the way Islamic equities respond to COVID-19 information flows relative to conventional equities; this resulted in the diversification prospects which were revealed in the short term and intermediate terms between equities from Jordan and Japan and Japan and UAE, respectively. The findings, to a large extent, support the EMH $[45,46]$ in the long run, but, in the short and medium run, they support the AMH [51], the HMH [52], and the CMH [8], all of which are anti-EMH. In the long run, where the underlying characteristics of the equities markets are operational, there is insufficient empirical evidence to reject the null hypothesis that "there exists no significant COVID-19 related information flow to the studied Islamic and conventional equities markets."

Generally, the findings suggest that, in response to market dynamics, investors modify their mood, risk, and reward preferences across time to fulfil their portfolio objectives. When the underlying structure of equity markets is displayed on the Residual horizon, COVID-19 provides only positive information to practically all markets, with few exceptions, but none of them is statistically significant. The insignificance of the positive flow sends an important message to all market participants. The pandemic (the number of confirmed cases and the resulting hysteria) has had little influence on the Islamic and conventional stock markets. The short- and intermediate-term market dynamics are attributable to irrational investor behaviour resulting from fear and paranoia linked with the pandemic, which the majority dismisses as noise $[8,104,105]$.

Due to the prevalent news concerning the pandemic, investors may have calmed down and achieved more balanced portfolios in the long run, so, intuitively, the pandemic may not have a significant impact on future investment and policy decisions for potential investors and policymakers within the Islamic and conventional stock markets. This is because the pandemic fails to impart any risk 
attributes (pleasant or unpleasant) of stocks to be evaluated or inculcated in allocating investible resources. In many aspects, this paradigm, in the long run, mirrors Fama's $[44,46]$ efficient market hypothesis $(\mathrm{EMH})$, in that the market actors' rationality is demonstrated despite the pandemic, corroborating the market's long-run efficiency [46].

In summary, the results provide insight into the significant implications of proven worldwide COVID-19 cases on selected Islamic and conventional stock markets. Accordingly, some policy implications are possible. First, legislators should pay greater attention to stock market swings as well as the number of verified COVID-19 cases, since they might affect market dynamics in the near term due to investor attitudes. In this instance, authorities should work out how to assist the market quickly and efficiently when the marginal number of COVID-19 confirmed cases is high. In severe instances, this may lessen the chance of a market crisis. Second, both local and worldwide events are likely to have an impact on investors. Consequential to clear and timely information concerning COVID-19, improved market predictions may occur. Investors and regulators should be increasingly worried about the risk of stock market comovements if the verified COVID-19 cases increase dramatically, since such integration would disparage diversification opportunities. Finally, the results provide advice to risk regulators on how to strengthen risk early warning systems by developing a daily monitoring technique for financial risk transmission across international borders. Risk regulators should employ management techniques that show how to use benefits, risk prevention, and risk management.

\section{Data Availability}

The data used in the study are publicly available and, thus, the author decided not to share them.

\section{Conflicts of Interest}

The author declares that he holds no direct or indirect conflicts of interest.

\section{References}

[1] K. J. Forbes and R. Rigobon, "No contagion, only interdependence: measuring stock market comovements," The Journal of Finance, vol. 57, no. 5, pp. 2223-2261, 2002.

[2] P. Owusu Junior, Emerging Financial Markets: Spatial Risks, Elicitability of Risk Models, and Shape Shift Contagion, University of the Witwatersrand, Johannesburg, South Africa, 2020.

[3] P. Owusu Junior, A. M. Adam, and G. Tweneboah, "Connectedness of cryptocurrencies and gold returns: evidence from frequency-dependent quantile regressions," Cogent Economics \& Finance, vol. 8, no. 1, Article ID 1804037, 2020.

[4] M. Arif, M. A. Naeem, M. Hasan, S. M Alawi, and F. Taghizadeh-Hesary, "Pandemic crisis versus global financial crisis: are Islamic stocks a safe-haven for G7 markets?” Economic Research-Ekonomska Istraživanja, vol. 34, pp. 1-21, 2021.
[5] E. Asafo-Adjei, P. Owusu Junior, and A. M. Adam, "Information flow between global equities and cryptocurrencies: a VMD-based entropy evaluating shocks from COVID-19 pandemic," Complexity, vol. 2021, Article ID 4753753, 25 pages, 2021.

[6] W. Mensi, M. Ur Rehman, D. Maitra, K. Hamed Al-Yahyaee, and A. Sensoy, "Does bitcoin co-move and share risk with Sukuk and world and regional Islamic stock markets? Evidence using a time-frequency approach," Research in International Business and Finance, vol. 53, Article ID 101230, 2020.

[7] S. K. Agyei, Z. Isshaq, S. Frimpong, A. M. Adam, A. Bossman, and O. Asiamah, "COVID-19 and food prices in sub-Saharan Africa," African Development Review, vol. 33, no. S1, pp. 1-12, 2021.

[8] P. Owusu Junior, S. Frimpong, A. M. Adam et al., "COVID19 as information transmitter to global equity markets: evidence from CEEMDAN-based transfer entropy approach," Mathematical Problems in Engineering, vol. 2021, Article ID 8258778, 19 pages, 2021.

[9] K. H. Al-Yahyaee, W. Mensi, M. U. Rehman, X. V. Vo, and S. H. Kang, "Do Islamic stocks outperform conventional stock sectors during no rmal and crisis periods? Extreme comovements and portfolio management analysis," PacificBasin Finance Journal, vol. 62, Article ID 101385, 2020.

[10] M. K. Hassan, H. G. Djajadikerta, T. Choudhury, and M. Kamran, "Safe havens in Islamic financial markets: COVID-19 versus GFC," Global Finance Journal, Article ID 100643, 2021.

[11] F. Balli, A. de Bruin, and M. I. H. Chowdhury, "Spillovers and the determinants in Islamic equity markets," The North American Journal of Economics and Finance, vol. 50, Article ID 101040, 2019.

[12] S. J. H. Shahzad, J. Arreola-Hernandez, S. Bekiros, M. Shahbaz, and G. M. Kayani, "A systemic risk analysis of Islamic equity markets using vine copula and delta CoVaR modeling," Journal of International Financial Markets, Institutions and Money, vol. 56, pp. 104-127, 2018.

[13] S. L. Ng, W. C. Chin, and L. L. Chong, "Realized volatility transmission within Islamic stock markets: a multivariate HAR-GARCH-type with nearest neighbor truncation estimator," Borsa Istanbul Review, vol. 20, pp. S26-S39, 2020.

[14] S. I. Abdullahi, "Islamic equities and COVID-19 pandemic: measuring Islamic stock indices correlation and volatility in period of crisis," Islamic Economic Studies, vol. 29, no. 1, pp. 50-66, 2021.

[15] S\&P Global, "Islamic finance 2020-2021: COVID-19 offers an opportunity for transformative developments," 2020, https://www.spglobal.com/ratings/en/research/articles/2006 15-islamic-finance-2020-2021-covid-19-offers-an-opportuni ty-for-transformative-developments-11533355.

[16] S. Ahmed, "Impact of COVID-19 on performance of Pakistan stock exchange," SSRN Electronic Journal, 2020.

[17] E. K. Chowdhury and M. Z. Abedin, "COVID-19 effects on the US stock index returns: an event study approach," SSRN Electronic Journal, 2020.

[18] B. Garg and K. P. Prabheesh, "The nexus between the exchange rates and interest rates: evidence from BRIICS economies during the COVID-19 pandemic," Studies in Economics and Finance, vol. 38, no. 2, 2021.

[19] W. Hanif, W. Mensi, and X. V. Vo, "Impacts of COVID-19 outbreak on the spillovers between US and Chinese stock sectors," Finance Research Letters, vol. 40, Article ID 101922, 2021. 
[20] N. T. Hung and X. V. Vo, "Directional spillover effects and time-frequency nexus between oil, gold and stock markets: evidence from pre and during COVID-19 outbreak," International Review of Financial Analysis, vol. 76, Article ID 101730, 2021.

[21] M. M. Karim, M. A. F. Chowdhury, and M. Masih, "Reexamining oil and BRICS'stock markets: new evidence from wavelet and MGARCH-DCC," Macroeconomics and Finance in Emerging Market Economies, vol. 1-19, 2021.

[22] K. Malik, S. Sharma, and M. Kaur, "Measuring contagion during COVID-19 through volatility spillovers of BRIC countries using diagonal BEKK approach," Journal of Economics Studies, 2021.

[23] P. K. Narayan, N. Devpura, and H. Wang, "Japanese currency and stock market-What happened during the COVID19 pandemic?" Economic Analysis and Policy, vol. 68, pp. 191-198, 2020.

[24] L. Yarovaya, A. H. Elsayed, and S. Hammoudeh, "Determinants of spillovers between Islamic and conventional financial markets: exploring the safe haven assets during the COVID-19 pandemic," Finance Research Letters, Article ID 101979, 2021.

[25] E. Asafo-Adjei, E. Boateng, Z. Isshaq, A. A.-A. Idun, P. Owusu Junior, and A. M. Adam, "Financial sector and economic growth amid external uncertainty shocks: insights into emerging economies," PLoS One, vol. 16, no. 11, Article ID e0259303, 2021.

[26] P. Owusu Junior, A. K. Tiwari, G. Tweneboah, and E. AsafoAdjei, "GAS and GARCH based value-at-risk modeling of precious metals," Resources Policy, vol. 75, Article ID 102456, 2022.

[27] T. L. D. Huynh, M. A. Nasir, X. V. Vo, and T. T. Nguyen, "“Small things matter most": the spillover effects in the cryptocurrency market and gold as a silver bullet," The North American Journal of Economics and Finance, vol. 54, Article ID 101277, 2020.

[28] J. Wu, T. Zhou, and T. Li, "A hybrid approach integrating multiple ICEEMDANs, WOA, and RVFL networks for economic and financial time series forecasting," Complexity in Finanace and economics, vol. 2020, 17 pages, Article ID 9318308, 2020.

[29] T. Li, Z. Qian, and T. He, "Short-term load forecasting with improved CEEMDAN and GWO-based multiple kernel ELM," Complexity, vol. 202020 pages, Article ID 1209547, 2020.

[30] Q. Peng, F. Wen, and X. Gong, “Time-dependent intrinsic correlation analysis of crude oil and the US dollar based on CEEMDAN," International Journal of Finance \& Economics, vol. 26, no. 1, pp. 834-848, 2021.

[31] Z. Kou, F. Yang, J. Wu, and T. Li, "Application of ICEEMDAN energy entropy and AFSA-SVM for fault diagnosis of hoist sheave bearing," Entropy, vol. 22, no. 12, p. 1347, 2020.

[32] F. Yang, Z. Kou, J. Wu, and T. Li, “Application of mutual information-sample entropy based MED-ICEEMDAN denoising scheme for weak fault diagnosis of hoist bearing," Entropy, vol. 20, no. 9, p. 667, 2018.

[33] Z. Huang, "Extensions to the k-means algorithm for clustering large data sets with categorical values," Data Mining and Knowledge Discovery, vol. 2, no. 3, pp. 283-304, 1998.

[34] M. A. Colominas, G. Schlotthauer, and M. E. Torres, "Improved complete ensemble EMD: a suitable tool for biomedical signal processing," Biomedical Signal Processing and Control, vol. 14, pp. 19-29, 2014.
[35] X. Navarro, F. Porée, and G. Carrault, "ECG removal in preterm EEG combining empirical mode decomposition and adaptive filtering," in Proceedings of the 2012 IEEE International Conference on Acoustics, Speech and Signal Processing (ICASSP), 661-664, April 2012.

[36] R. Fontugne, J. Ortiz, N. Tremblay et al., "Strip, bind, and search: a method for identifying abnormal energy consumption in buildings," in Proceedings of the 2013 ACM/ IEEE International Conference on Information Processing in Sensor Networks (IPSN), pp. 129-140, IEEE, Philadelphia, PA, USA, April 2013.

[37] J. Han and M. Van der Baan, "Empirical mode decomposition for seismic time-frequency analysis," Geophysics, vol. 78, no. 2, pp. O9-O19, 2013.

[38] A. Hooshmand, J. Nasseri, and H. R. Siahkoohi, "Seismic data denoising based on the complete ensemble empirical mode decomposition," in Proceedings of the Istanbul 2012International Geophysical Conference and Oil \& Gas Exhibition, pp. 1-4, Society of Exploration Geophysicists and The Chamber of Geophysical Engineers of Turkey, Istanbul,Turkey, September 2012.

[39] M. A. Colominas, G. Schlotthauer, P. Flandrin, and M. E. Torres, Descomposición empírica en modos por conjuntos completa con ruido adaptativo y aplicaciones biomédicas, XVIII Congreso Argentino de Bioingeniería y VII Jornadas de Ingeniería Clínica, Mar Del Plata, Argentina, 2011.

[40] M. E. Torres, M. A. Colominas, G. Schlotthauer, and P. Flandrin, "A complete ensemble empirical mode decomposition with adaptive noise," in Proceedings of the 2011 IEEE International Conference on Acoustics, Speech and Signal Processing (ICASSP), pp. 4144-4147, IEEE, Prague, Czech Republic, May 2011.

[41] A. M. Adam, "Susceptibility of stock market returns to international economic policy: evidence from effective transfer entropy of Africa with the implication for open innovation," Journal of Open Innovation: Technology, Market, and Complexity, vol. 6, no. 3, p. 71, 2020.

[42] S. Lahmiri and S. Bekiros, "The impact of COVID-19 pandemic upon stability and sequential irregularity of equity and cryptocurrency markets," Chaos, Solitons \& Fractals, vol. 138, Article ID 109936, 2020.

[43] T. Dimpfl and F. J. Peter, "Using transfer entropy to measure information flows between financial markets," Studies in Nonlinear Dynamics and Econometrics, vol. 17, no. 1, pp. 85-102, 2013.

[44] E. F. Fama, L. Fisher, M. C. Jensen, and R. Roll, "The adjustment of stock prices to new information," International Economic Review, vol. 10, no. 1, pp. 1-21, 1969.

[45] E. F. Fama, "Efficient capital markets: a review of theory and empirical work," The Journal of Finance, vol. 25, no. 2, pp. $383-417,1970$.

[46] E. F. Fama, "Market efficiency, long-term returns and behavioural finance," The Journal of Finance, vol. 25, pp. 383-417, 1998.

[47] S. Benthall, "Situated information flow theory," in Proceedings of the 6th Annual Symposium on Hot Topics in the Science of Security - HotSoS '19, Nashville Tennessee USA, April 2019.

[48] D. Odegard, "Knowledge and the flow of InformationFred I. Dretske cambridge, MA: MIT press, 1981. Pp. Xiv, 273. \$18.50 (U.S.)," Dialogue, vol. 21, no. 4, pp. 778-779, 1982.

[49] J. Pearl, "Causal inference in statistics: an overview," Statistics Surveys, vol. 3, pp. 96-146, 2009. 
[50] H. Markowitz, "Portfolio selection," The Journal of Finance, vol. 7, no. 1, pp. 77-91, 1952.

[51] A. W. Lo, "The adaptive markets hypothesis," Journal of Portfolio Management, vol. 30, no. 1, pp. 15-29, 2004, https:// scholar.google.com/scholar?hl=en\&as_sdt $=0 \% 2 \mathrm{C} 5 \& \mathrm{q}=\mathrm{Lo} \%$ 2C+A.+W.+\%282004\%29.+Lo.

+The+adaptive+markets+hypothesis.

+The+journal+of+portfolio+management $\% 2 \mathrm{C}+30 \% 285 \%$ $29 \% 2 \mathrm{C}+15-29$.

[52] U. A. Müller, M. M. Dacorogna, R. D. Davé, O. V. Pictet, R. B. Olsen, and J. R. Ward, Fractals and Intrinsic Time: A challenge to Econometricians, Unpublished Manuscript, p. 130, Olsen \& Associates, Zürich, Switzerland, Olsen \& Associates, 1993.

[53] A. M. Adam, E. N. Gyamfi, K. A. Kyei, S. Moyo, and R. S. Gill, "A new EEMD-effective transfer entropy-based methodology for exchange rate market information transmission in Southern Africa Development Community," Complexity, vol. 2021, Article ID 3096620, 22 pages, 2021.

[54] A. M. Adam, K. Kyei, S. Moyo, R. Gill, and E. N. Gyamfi, "Multifrequency network for SADC exchange rate markets using EEMD-based DCCA," Journal of Economics and Finance, 2021.

[55] A. M. Adam, K. Kyei, S. Moyo, R. Gill, and E. N. Gyamfi, "Similarities in Southern African Development Community (SADC) exchange rate markets structure: evidence from the ensemble empirical mode decomposition," Journal of African Business, vol. 22, pp. 1-16, $2021 \mathrm{~b}$.

[56] S. J. H. Shahzad, R. Ferrer, L. Ballester, and Z. Umar, "Risk transmission between Islamic and conventional stock markets: a return and volatility spillover analysis," International Review of Financial Analysis, vol. 52, pp. 9-26, 2017.

[57] Z. Umar, "Islamic vs conventional equities in a strategic asset allocation framework," Pacific-Basin Finance Journal, vol. 42, pp. 1-10, 2017.

[58] Z. Umar and T. Suleman, "Asymmetric return and volatility transmission in conventional and Islamic equities," Risks, vol. 5, no. 2, p. 22, 2017.

[59] Z. Umar, S. J. H. Shahzad, R. Ferrer, and F. Jareño, "Does Shariah compliance make interest rate sensitivity of Islamic equities lower? An industry level analysis under different market states," Applied Economics, vol. 50, no. 42, pp. 4500-4521, 2018.

[60] Z. Umar, S. Aziz, and D. Tawil, "The impact of COVID-19 induced panic on the return and volatility of precious metals," Journal of Behavioral and Experimental Finance, vol. 31, Article ID 100525, 2021.

[61] Z. Umar, M. Gubareva, and T. Sokolova, "The impact of the COVID-19 related media coverage upon the five major developing markets," PLoS One, vol. 16, no. 7, Article ID e0253791, 2021.

[62] Z. Umar, M. Gubareva, and T. Teplova, "The impact of COVID-19 on commodity markets volatility: analyzing time-frequency relations between commodity prices and coronavirus panic levels," Resources Policy, vol. 73, Article ID 102164, 2021.

[63] Z. Umar, M. Gubareva, D. K. Tran, and T. Teplova, "Impact of the COVID-19 induced panic on the environmental, social and governance leaders equity volatility: a time-frequency analysis," Research in International Business and Finance, vol. 58, Article ID 101493, 2021.

[64] Z. Umar, F. Jareño, and A. Escribano, "Dynamic return and volatility connectedness for dominant agricultural commodity markets during the COVID-19 pandemic era," Applied Economics, pp. 1-25, 2021.

[65] Z. Umar, F. Jareño, and M. D. L. O. González, "The impact of COVID-19-related media coverage on the return and volatility connectedness of cryptocurrencies and fiat currencies," Technological Forecasting and Social Change, vol. 172, Article ID 121025, 2021.

[66] Z. Umar and M. Gubareva, "The relationship between the COVID-19 media coverage and the Environmental, Social and Governance leaders equity volatility: a time-frequency wavelet analysis," Applied Economics, vol. 53, no. 27, pp. 3193-3206, 2021.

[67] Z. Umar and M. Gubareva, "A time-frequency analysis of the impact of the Covid-19 induced panic on the volatility of currency and cryptocurrency markets," Journal of Behavioral and Experimental Finance, vol. 28, Article ID 100404, 2020.

[68] Z. Umar and M. Gubareva, "Faith-based investments and the COVID-19 pandemic: analyzing equity volatility and media coverage time-frequency relations," Pacific-Basin Finance Journal, vol. 67, Article ID 101571, 2021.

[69] A. Zaremba, R. Kizys, D. Y. Aharon, and Z. Umar, “Term spreads and the COVID-19 pandemic: evidence from international sovereign bond markets," Finance Research Letters, Article ID 102042, 2021.

[70] M. Akhtaruzzaman, S. Boubaker, and Z. Umar, "COVID-19 media coverage and ESG leader indices," Finance Research Letters, Article ID 102170, 2021.

[71] M. Gubareva and Z. Umar, "Emerging market debt and the COVID-19 pandemic: a time-frequency analysis of spreads and total returns dynamics," International Journal of Finance \& Economics, 2020.

[72] W. Yunhong, L. Guosui, L. Xi, and W. Yiding, "A pattern recognition method based on short-time Fourier transform and sigular values feature extraction," Signal Processing, vol. 2, 1998.

[73] G. B. Hu, Y. Liu, and Z. M. Deng, "Arrival time estimation of signals based on Haar wavelets transform," Systems Engineering and Electronics, vol. 31, no. 7, pp. 1615-1619, 2009.

[74] R. Liao, C. Guo, K. Wang, Z. Zuo, and A. Zhuang, "Adaptive optimal kernel time-frequency representation technique for partial discharge ultra-high-frequency signals classification," Electric Power Components and Systems, vol. 43, no. 4, pp. 449-460, 2015.

[75] X. Wang, J. Gao, W. Chen, J. Xu, W. Zhao, and X. Jiang, "Adaptive optimal-kernel time-frequency representation and its application in characterizing seismic attenuation," in Proceedings of the 2011 SEG Annual Meeting, San Antonio, TX, USA, January 2011.

[76] P. Owusu Junior and G. Tweneboah, "Are there asymmetric linkages between African stocks and exchange rates?" Research in International Business and Finance, vol. 54, Article ID 101245, 2020.

[77] X. Xiao, J. He, H. Huang et al., "A novel single-parameter approach for forecasting algal blooms," Water Research, vol. 108, pp. 222-231, 2017.

[78] T. Schreiber, "Measuring information transfer," Physical Review Letters, vol. 85, no. 2, pp. 461-464, 2000.

[79] S. Lahmiri and S. Bekiros, "Randomness, informational entropy, and volatility interdependencies among the major world markets: the role of the COVID-19 pandemic," Entropy, vol. 22, no. 8, p. 833, 2020.

[80] J. Wang and X. Wang, "Covid-19 and financial market efficiency: evidence from an entropy-based analysis," Finance Research Letters, vol. 42, Article ID 101888, 2021. 
[81] P. Ferreira, A. Dionísio, D. Almeida, D. Quintino, and F. Aslam, "A new vision about the influence of major stock markets in CEEC indices: a bidirectional dynamic analysis using transfer entropy," Post-communist Economies, pp. 116, 2021.

[82] P. Ferreira, D. Almeida, A. Dionísio, E. Bouri, and D. Quintino, "Energy markets - who are the influencers?" Energy, vol. 239, Article ID 121962, 2022.

[83] S. I. Ivanov, "The influence of ETFs on the price discovery of gold, silver and oil," Journal of Economics and Finance, vol. 37, no. 3, pp. 453-462, 2013.

[84] J. B. Ramsey and C. Lampart, "The decomposition of economic relationships by time scale using wavelets: expenditure and income," Studies in Nonlinear Dynamics \& Econometrics, vol. 3, no. 1, 1998.

[85] B. Yang, Y. Sun, and S. Wang, "A novel two-stage approach for cryptocurrency analysis," International Review of Financial Analysis, vol. 72, Article ID 101567, 2020.

[86] P. J. J. Luukko, J. Helske, and E. Räsänen, "Introducing libeemd: a program package for performing the ensemble empirical mode decomposition," Computational Statistics, vol. 31, no. 2, pp. 545-557, 2016.

[87] P. Flandrin, G. Rilling, and P. Gonçalvés, "Empirical mode decomposition as a filter bank," IEEE Signal Processing Letters, vol. 11, no. 2, pp. 112-114, 2004.

[88] R. J. Gledhill, Methods for Investigating Conformational Change in Biomolecular Simulations, University of Southampton, Southampton, UK, 2004.

[89] Z. Wu and N. E. Huang, "Ensemble empirical mode decomposition: a noise-assisted data analysis method," Advances in Adaptive Data Analysis, vol. 01, no. 1, pp. 1-41, 2009.

[90] R. V. L. Hartley, “Transmission of Information1," Bell System Technical Journal, vol. 7, no. 3, pp. 535-563, 1928.

[91] S. Behrendt, T. Dimpfl, F. J. Peter, and D. J. Zimmermann, "RTransferEntropy - quantifying information flow between different time series using effective transfer entropy," Software, vol. 10, Article ID 100265, 2019.

[92] C. E. Shannon, "A mathematical theory of communication," Bell System Technical Journal, vol. 27, no. 3, pp. 379-423, 1948.

[93] S. Kullback and R. A. Leibler, "On information and sufficiency," The Annals of Mathematical Statistics, vol. 22, no. 1, pp. 79-86, 1951.

[94] A. Rényi, "On measures of entropy and information," in Proceedings of the Fourth Berkeley Symposium on Mathematical Statistics and Probability, Volume 1: Contributions to the Theory of Statistics, pp. 547-561, University of California Press, Berkeley, CA, USA, July 1961.

[95] C. Beck and F. Schögl, Thermodynamics of Chaotic Systems, Cambridge University Press, Cambridge, UK, 1995.

[96] R. Marschinski and H. Kantz, "Analysing the information flow between financial time series," The European Physical Journal B, vol. 30, no. 2, pp. 275-281, 2002.

[97] S. J. Salyer, J. Maeda, S. Sembuche et al., "The first and second waves of the COVID-19 pandemic in Africa: a cross-sectional study," The Lancet, vol. 397, no. 10281, pp. 1265-1275, 2021.

[98] B. Sander, A. Nizam, L. P. Garrison, M. J. Postma, M. E. Halloran, and I. M. Longini, "Economic evaluation of influenza pandemic mitigation strategies in the United States using a stochastic microsimulation transmission model," Value in Health, vol. 12, no. 2, pp. 226-233, 2009.
[99] E. J. d. A. L. Pereira, P. J. S. Ferreira, M. F. d. Silva, J. G. V. Miranda, and H. B. B. Pereira, "Multiscale network for 20 stock markets using DCCA," Physica A: Statistical Mechanics and its Applications, vol. 529, Article ID 121542, 2019.

[100] J. Bouoiyour, R. Selmi, A. K. Tiwari, and O. R. Olayeni, "What drives Bitcoin price," Economics Bulletin, vol. 36, no. 2, pp. 843-850, 2016.

[101] J. Bouoiyour, R. Selmi, and M. E. Wohar, "Safe havens in the face of Presidential election uncertainty: a comparison between Bitcoin, oil and precious metals," Applied Economics, vol. 51, no. 57, pp. 6076-6088, 2019.

[102] P. O. Junior, A. K. Tiwari, H. Padhan, and I. Alagidede, "Analysis of EEMD-based quantile-in-quantile approach on spot- futures prices of energy and precious metals in India," Resources Policy, vol. 68, Article ID 101731, 2020.

[103] P. Owusu Junior, I. Alagidede, and G. Tweneboah, "Shapeshift contagion in emerging markets equities: evidence from frequency- and time-domain analysis," Economics and Business Letters, vol. 9, no. 3, pp. 146-156, 2020.

[104] B. Cornell, "What is the alternative hypothesis to market efficiency?" Journal of Portfolio Management, vol. 44, no. 7, pp. 3-6, 2018.

[105] H. Hassani, A. Dionisio, and M. Ghodsi, "The effect of noise reduction in measuring the linear and nonlinear dependency of financial markets," Nonlinear Analysis: Real World Applications, vol. 11, no. 1, pp. 492-502, 2010. 